\title{
Water splitting mediated by an electrocatalytically driven cyclic process involving iron oxide species
}

Marten Huck ${ }^{\mathrm{a}}$, Lisa Ring ${ }^{\mathrm{a}}$, Karsten Küpper ${ }^{\mathrm{b}}$, Johann Klare ${ }^{\mathrm{b}}$, Diemo Daumc, and Helmut Schäfer ${ }^{\mathrm{a} *}$ anstitute of Chemistry of New Materials, The Electrochemical Energy and Catalysis group, University of Osnabrück, Barbarastrasse 7, 49076 Osnabrück, Germany bDepartment of Physics, Universität Osnabrück, Barbarastrasse 7, 49076 Osnabrück, Germany

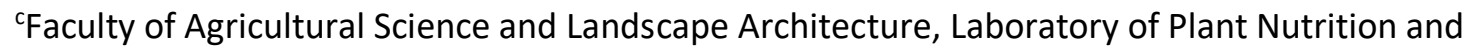
Chemistry, Osnabrück University of Applied Sciences, Am Krümpel 31, D-49090 Osnabrück, Germany E-mail:helmut.schaefer@uos.de

Dedicated to Prof. Dr. Siegfried Pohl, Carl von Ossietzky Universität Oldenburg († 18.12.1996)

Abstract: For a good reason, water splitting is the most pioneering energy storage technology. However, particularly water electrolysis still has a shadow existence compared to currently used methods for mass production of hydrogen. All known materials currently exploited as anodes for the electrocatalytically initiated water-splitting suffer from high overpotentials and substantial mass loss whilst long term operation in acidic media. Low electrode stability affects operating- and maintenance costs and together with high overpotentials directly lowers the overall efficiency of electrocatalytically driven splitting of water. In circumventing these problems, scientists and engineers are currently modifying the electrode materials. We chose a completely different path and modified the electrolyte. An electrolysis set up, that consists of a Ni42 stainless steel anode and of hematite which is suspended in high concentration in sulfuric acid and acts as electrolyte, exhibits oxygen evolution electrocatalysis at extremely low potential ( $1.26 \mathrm{~V} v$ s. $\mathrm{RHE} ; 0.5 \mathrm{M} \mathrm{H}_{2} \mathrm{SO}_{4}, \mathrm{j}=30$ $\mathrm{mA} / \mathrm{cm}^{2}$ ). If implemented in a suitable electrolyzer an ultralow cell voltage of $1,6 \mathrm{~V}$ and an almost quantitatively charge to oxygen + hydrogen conversion rate was achieved. Remarkably the negligible mass loss of the anode that solely consists of non-platinum group metals (non-PGM) whilst $100 \mathrm{~h}$ of operation. Experiments aimed at clarifying the mechanism suggest that $\mathrm{Fe}_{2} \mathrm{O}_{3}$ is converted to a $\mathrm{Fe}(\mathrm{II}) / \mathrm{Fe}(\mathrm{III})$ oxide species on the cathode which is then reconverted to $\mathrm{Fe}_{2} \mathrm{O}_{3}$ upon release of 
molecular oxygen when touching the anode. As a result, the oxygen-evolving centers are likely to be on the oxide particles rather than on the electrode. This proposed mechanism would explain the low potential of the OER electrode $\left(+1,26 \mathrm{~V} v \mathrm{~s}\right.$. RHE at $\left.\mathrm{j}=30 \mathrm{~mA} / \mathrm{cm}^{2}\right)$ that could not be explained convincingly by an assumed direct oxidation of water molecules.

\section{Introduction}

Besides the limited availability of fossil fuels, the greenhouse gas production upon burning of oil and gas forces scientists and engineers to search for alternative (green) energy carriers that are produced $\mathrm{CO}_{2}$ footprint free, i.e. produced as much as possible through the uses of renewable energy resources like wind, solar, hydropower or geothermal ${ }^{1,2,3,4}$. Hydrogen has future potential as an energy carrier due to its high energy content and its harmless burning products. Electrocatalytically initiated water splitting, if sourced by green electricity, allows a reasonable, while $\mathrm{CO}_{2}$ footprint free, access to clean hydrogen and oxygen, the fuel with which a fuel cell can be run $5,6,7,8,9,10$. The usefulness of electrocatalytically driven $\mathrm{H}_{2} / \mathrm{O}_{2}$ production stands or falls with its efficiency which is in turn directly determined by the overpotentials occurring on the anode and the cathode side where oxygen evolution (OER) and hydrogen evolution (HER) takes place ${ }^{11}$. Ascribable to the sluggish kinetics of the corresponding half-cell reaction, oxygen evolving electrodes contribute mainly to the surplus of cell voltage which must be applied in addition to the theoretical decomposition voltage (1.228 V) of water electrolysis. Therefore, the OER is the main source for overvoltage ${ }^{12,13,14}$. This especially comes into play when electrocatalytic water oxidation is intended at low $\mathrm{pH}$ value.

While in alkaline media none platinum group metal (none PGM) containing electrodes can be regarded as permanent and stable OER-supporting electrocatalysts which show no significant weight loss with long-term use and at the same time ensure a current density of $10 \mathrm{~mA} / \mathrm{cm}^{2}$ at overpotentials in the $200 \mathrm{mV}$ range ${ }^{15,16}$, this is nowhere near the case when water splitting in acids is intended ${ }^{17,18}$. It can be assumed that these effects are largely responsible for the fact that water electrolysis still has a shadow existence compared to the current techniques for mass production of hydrogen. In terms of practical applicability in large scale and adaptivity to frequent changes of the 
current load, electrodes that can withstand an acidic environment are beneficial: Thus, proton exchange membrane (PEM) electrolyzers which require acidic stable electrode materials are seen as the method of choice for the storage of renewable energy characterized by high dynamics ${ }^{19}$. This is due to several advantages, in the main PEM has an extremely low permeability to hydrogen and this ensures a very high purity of the output hydrogen stream, while removing the safety issues associated with gas mixing which is a substantial problem when e.g. alkaline electrolyzers have to run temporarily under a wide range of partial load. The attractivity of PEM type electrolyzers pushes scientists and engineers to develop OER electrode materials actively and durably working in acidic regime. In view of the highly corrosive environment in combination with oxidative potentials, it is easy to understand that these requirements of electrodes, which preferably consist of non-noble elements, are difficult to meet.

Thus for instance in terms of surface-modified steel, which corresponds to our expertise, overpotentials of $550 \mathrm{mV}^{17}, 574 \mathrm{mV}^{18}$ respectively, at $\mathrm{pH} 1$ and $\mathrm{j}=10 \mathrm{~mA} / \mathrm{cm}^{2}$ derived from chronopotentiometry (CP) data were assigned to electro-activated Ni-based ${ }^{17}$ and Co- based ${ }^{18}$ stainless steels. Even more so a reason to complain: The significant mass loss of the steel anode when it promotes OER in $0.05 \mathrm{M} \mathrm{H}_{2} \mathrm{SO}_{4}$ which amounted to $20 \mu \mathrm{g} / \mathrm{mm}^{2}$ (Ni-based steel) ${ }^{17} 39 \mu \mathrm{g} / \mathrm{mm}^{2}$ (Co-based steel) $)^{18}$ after 50000 s of CP at only $10 \mathrm{~mA} / \mathrm{cm}^{2}$ current density.

Generally, oxides of nickel and cobalt have proven to be unstable in acidic regime when positive potentials have been applied ${ }^{20,21}$. Especially Ir-oxide and Ru-oxide as well as $\mathrm{IrO}_{2}-\mathrm{RuO}_{2}$ were found to be substantially more active and durable towards OER electrocatalytically promoted in acids ${ }^{17,18 \text {, }}$ $21,22,23$. Not least because of the scarcity and (as a consequence thereof) the high price, the need for large quantities of these substances should be limited. Diluting the expensive components of the electro-catalyst like e.g. Ru or Ir by simply adding "more commonplace" elements is a reasonable and obvious approach to circumventing this problem. This strategy was realized by various groups $24,25,26$, 27. To the best of the authors knowledge the best OER performance achieved in acids at $\mathrm{pHO}$ upon using this strategy $\left(\mathrm{IrOx} / \mathrm{SrlrO}_{3}\right)$ was shown by Seitz et al. $(\eta=280 \mathrm{mV} \text { at } 10 \mathrm{~mA} \mathrm{~cm}-2)^{26}$. Leakage of 
Sr out of the material during the first 2 hours of electrochemical testing goes hand in hand with an increment of its activity towards OER. However, it appears reasonable to assume that leakage of $\mathrm{Sr}$ out of the anode continues when positive potentials are applied for a long time in acidic regime. For ternary Sr-Ir-O compounds substantial leakage of Sr besides smaller amounts of Ir upon usage as OER electrodes in acids was confirmed recently ${ }^{28}$ exhibiting that even under current-less condition e.g. $\mathrm{SrlrO}_{3}$ dissolves in acid.

Instead of developing new catalytically active layers, new self-supported OER electrodes or designing new substrate/active layer combinations we decided to take a different, new path and modified the electrolyte.

The original intent of this study was to direct the oxygen evolution centers (and the material removal they cause) away from the electrode to particles suspended in the acid-based electrolyte. Iron oxide is of potential interest since Fe can exist in two different oxidation states, both of which can be achieved in aqueous systems. Besides, the ability of iron oxide-based species such as $\mathrm{Fe}_{2} \mathrm{O}_{3}$ or $\mathrm{Fe}_{3} \mathrm{O}_{4}$ to promote catalytic splitting of water molecules is well known ${ }^{29,30,31}$. Magnetite particles suspended in an electrolyte however have a considerable drawback. They are magnetic and therefore crowd around the stir bar. Hematite $\left(\mathrm{a}-\mathrm{Fe}_{2} \mathrm{O}_{3}\right)$ proved to be the material of choice due to its remarkable stability in an aqueous environment, its low cost and its high element frequency. With a band gap of $2.1 \mathrm{eV}$ hematite is preferably used as a photoanode material ${ }^{32,33}$.

Nano-scaled hematite suspended in sulfuric acid turned out to substantially influence the current voltage behavior of a known electrode configuration consisting of stainless-steel electrodes whilst water electrolysis at low $\mathrm{pH}$ values

The chosen design ensured electrocatalytic water oxidation on stainless steel, demonstrating a tremendous, hitherto unprecedented efficiency and stability. 


\section{Results and discussion}

Water electrolysis was performed in $0.5 \mathrm{M}$ sulfuric acid under strong stirring upon using a threeelectrode set-up consisting of a Ni42 steel electrode exploited as anode (working electrode, WE), a platinum cathode (counter electrode, $\mathrm{CE}$ ) as well as of a reversible hydrogen electrode (positioned between WE and $\mathrm{CE}$ ) used as reference electrode (RE). A chronopotentiometry measurement was started at a total current of $300 \mathrm{~mA}$ which corresponds to $150 \mathrm{~mA} / \mathrm{cm}^{2}$ current density (electrode area: $\left.2 \mathrm{~cm}^{21}\right)$. As expected, the potential required to ensure this strong current flow amounted to values substantially above 2 V vs. RHE (Sample 1; Figure 1a, blue curve). After 10000 s the current density was reduced to $150 \mathrm{~mA} / \mathrm{cm}^{2}$, after additional $600 \mathrm{~s}$ to $30 \mathrm{~mA} / \mathrm{cm}^{2}$, respectively. As expected, the corresponding potential was found to be reduced in steps as well, and finally reached a constant value of $1.90 \mathrm{~V} v s$. RHE which seems to be reasonable in light of earlier results ( $1.935 \mathrm{~V} v$ s. RHE at 10 $\mathrm{mA} / \mathrm{cm}^{2}$ at $\mathrm{pH} 1$ ) derived from OER tests carried out under steady state conditions with untreated steel Ni42 in acids ${ }^{17}$. Ni42 steel contains around $42 \mathrm{wt}$. \% $\mathrm{Ni}$ and showed also in alkaline regime without any treatment a considerable OER activity in earlier studies, thus e.g. in $0.1 \mathrm{M} \mathrm{KOH} \mathrm{(} \eta=347$ $\mathrm{mV}$ at $10 \mathrm{~mA} / \mathrm{cm}^{2}$ ) due to the formation of $\gamma-\mathrm{NiOOH}$ on the very surface ${ }^{15,47}$. Properly electroactivated it exhibited good OER performance over a wide $\mathrm{pH}$ range ${ }^{47}$. In a comparative experiment (sample 8), carried out under similar conditions, the clear electrolyte was replaced by a suspension. Hematite was suspended in $0.5 \mathrm{M}$ sulfuric acid at relatively high concentration ( 28 wt. \%) to form a deep red suspension (Figure $1 \mathrm{~b}$; details see experimental section). The potential required to result in $150 \mathrm{~mA} / \mathrm{cm}^{2}$ and $75 \mathrm{~mA} / \mathrm{cm}^{2}$ current density ( $300 \mathrm{~mA}$ and $150 \mathrm{~mA}$ total current; first 3 hours of the experiment) was comparable to the one derived from the experiment performed in pure sulfuric acid (Figure 1a, black and blue curve). The potential that corresponds to $\mathrm{j}=30 \mathrm{~mA} / \mathrm{cm}^{2}$ is at the beginning somewhat lower than derived from clear electrolytebased measurements and, in addition, turned out to be not constant (Figure 1a, black curve). At the beginning of the "30 $\mathrm{mA} / \mathrm{cm}^{2}$ region", the curve drops off flat. Then the potential drops abruptly and turns into a slightly sloping curve which, after a while, transitions to the horizontal, indicating a 
steady value of about 1.26 V vs. RHE (Figure 1a, black curve) which corresponds to an overpotential of around $30 \mathrm{mV}$ (at j=30 mA/cm in $0.5 \mathrm{M} \mathrm{H}_{2} \mathrm{SO}_{4}$ ) with respect to the water oxidation reaction. The dynamic voltage-current characteristics derived from the electrolysis of the suspension (sample 8) was determined at the beginning of the experiment (Figure 1c) as well as after around $60000 \mathrm{~s}$ of electrolysis (Figure 1d) and confirmed the ones drawn from the experiments carried out under steady state conditions.

This experiment was repeated 44 times and within the series of experiments the composition of the electrolyte, the stirring rate and the duration of chronopotentiometric steps were varied (Table S1). In half of the experiments the Pt CE was replaced by a Ni42 electrode which was found to have no influence on the anode half-cell potential of the set-up. 
a)

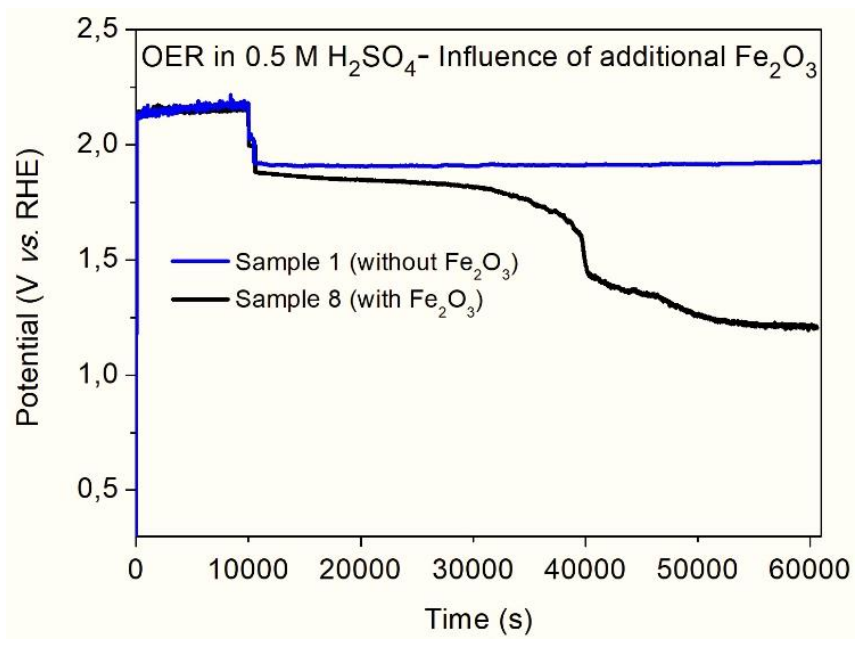

c)

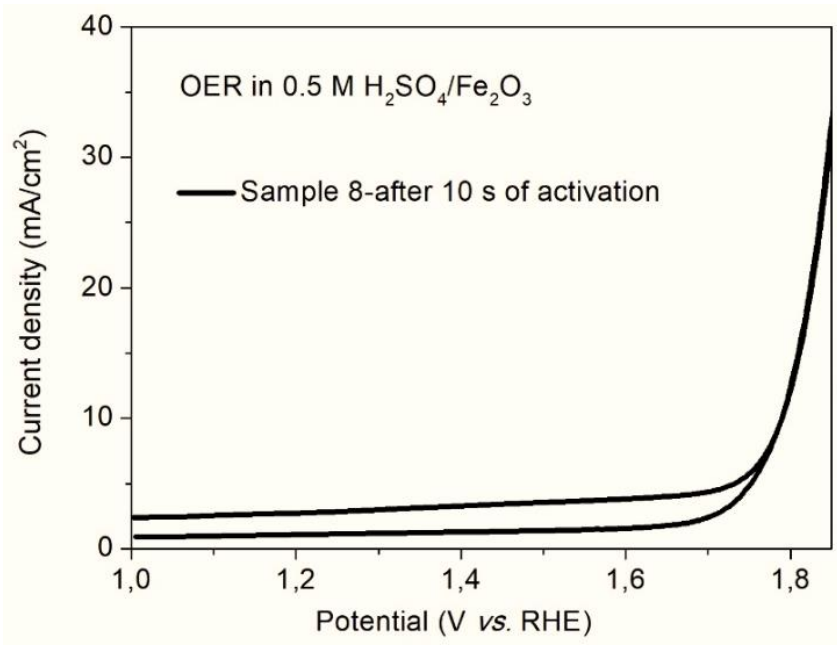

b)

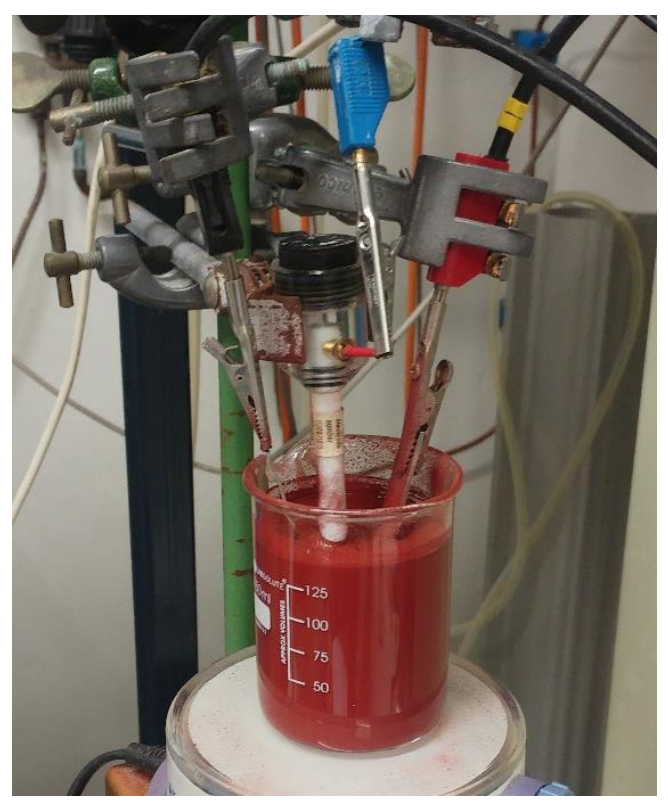

d)

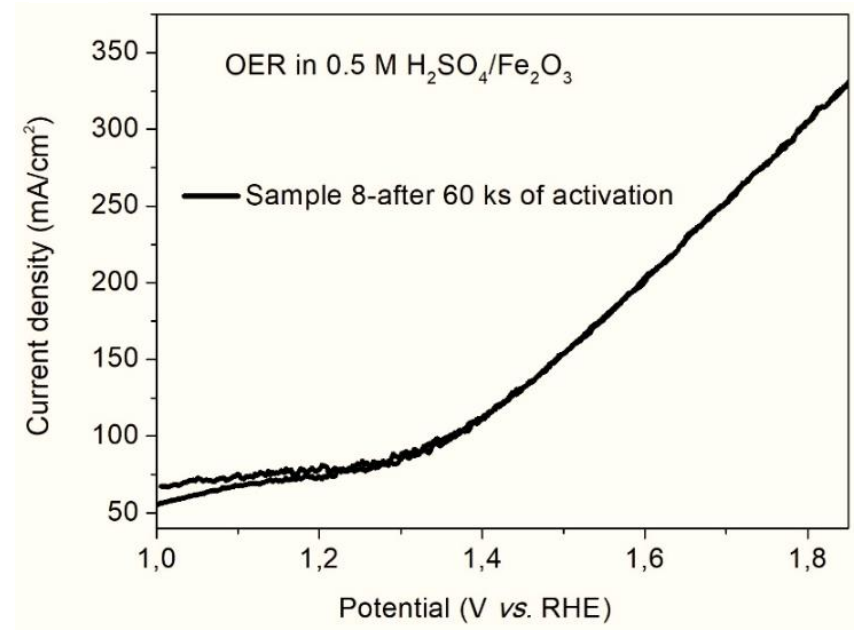

Figure 1. (a)Chronopotentiometry measurement of samples 1 and 8 (Table S1) without (sample 1) or with $\mathrm{Fe}_{2} \mathrm{O}_{3}$ (sample 8) added to the $\mathrm{H}_{2} \mathrm{SO}_{4}$ electrolyte. Stirring rate: 4.5. (b) Photo of the electrolysis set up. (c) Cyclic voltammetry scan of sample 8 after 10 s of activation (CP) as seen in Figure 1a. (d) Cyclic voltammetry scan of sample 8 after $60000 \mathrm{~s}$ of activation (CP) as seen in Figure 1a.

The weight loss of the Ni42 anode whilst preparing samples 1, 2, 9, 10, 12, 13, 14, 15, 16, 17 and 18 i.e. after completion of the first electrolysis step (current protocol I) was determined (Table S1; last column). We explicitly point out that this does not present the mass deficit the completed samples show when used as OER electrocatalyst under long term operation at constant current density which 
will be discussed later. In parallel to determining the weight loss, the corresponding electrolyte was analyzed after completion of current protocol I via ICP-OES. Figure 2a presents a comparison of the weight loss of the Ni42 anodes with the sum of the mass of ions detected in the electrolyte. At a glance, it can be seen that in each case studied, the sum of the material detected in the electrolyte exceeds the weight loss of the anode many times over. This finding proves that the overwhelming part of the material dissolved in the electrolyte has its origin in the suspended hematite. Figure $2 b$ displays the composition of the substance found in the acidic electrolyte of samples 1, 2, 9, 10, 12-18. It can be clearly seen, that Fe ions are the dominating ionic species. The total mass of iron detected in the electrolyte exceeds that of $\mathrm{Ni}$ by a (mean) factor of 22 . 
a)

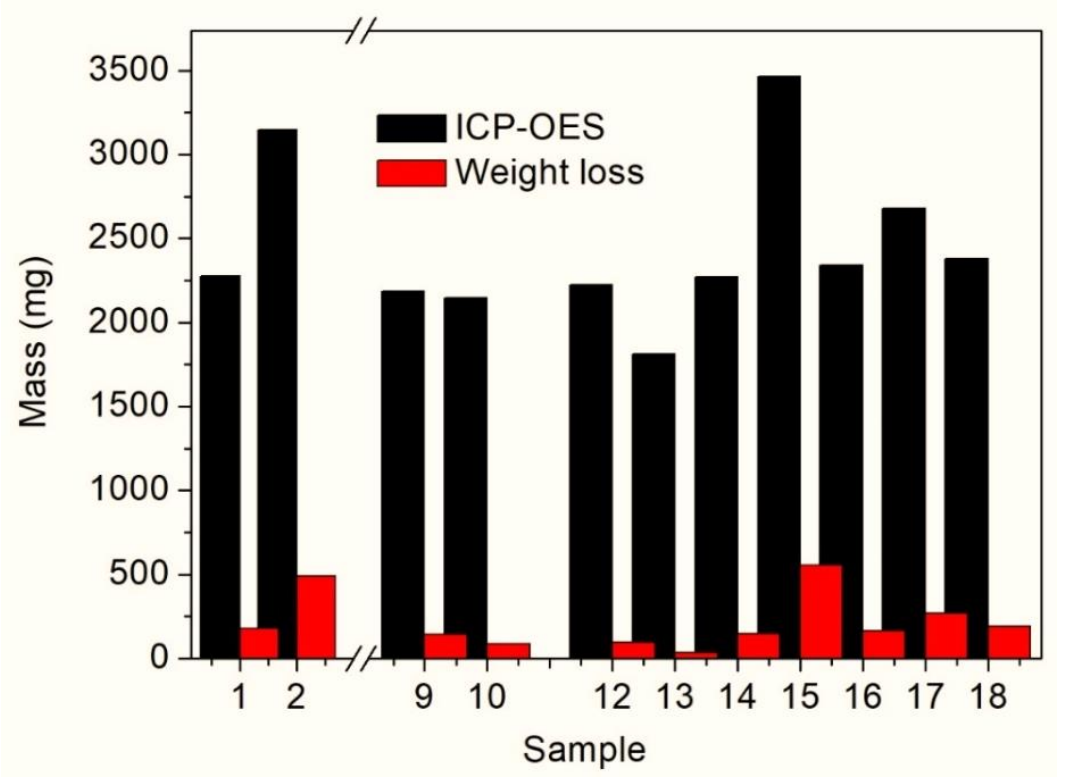

b)

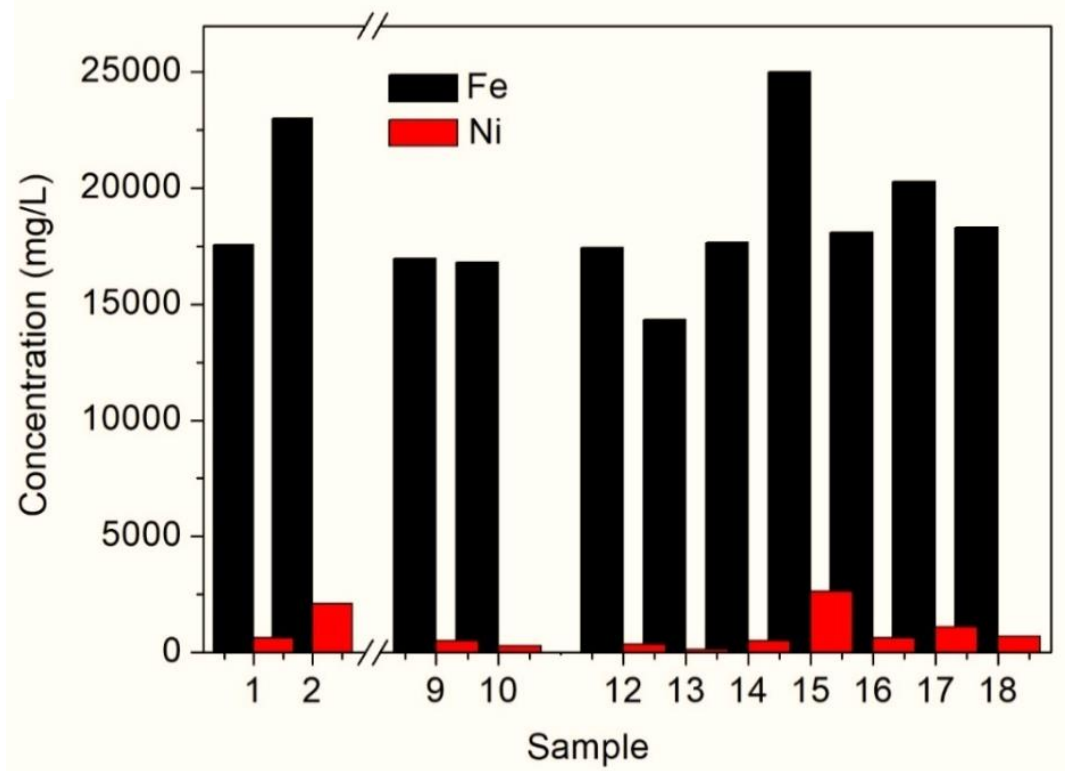

Figure 2a. A comparison of the amount of material detected via ICP-OES in the electrolyte (black columns) with the weight loss of the Ni42 steel electrode that occurs whilst activation in sulfuric acid (red columns). Figure $2 \mathrm{~b}$. The composition of the material dissolved in the sulfuric acid electrolyte used for polarization leading to samples 1,2,9,10,12-18.

Although not every identical set of experimental parameters leads to an absolutely identical voltage/current behavior of CP experiments, the reproducibility can be regarded as very good (Table 
S1; Figures S1-S27). A common feature of all voltage-current characteristics of the chronopotentiometry measurements derived from suspension-based approaches: the potential required to result in $30 \mathrm{~mA} / \mathrm{cm}^{2}$ anodic current density was after some while found to be reduced to a value of roughly $1.26 \mathrm{~V} v$ s. RHE. The overall cell voltage amounted after some while to $1.60 \mathrm{~V}$ at $\mathrm{j}=$ $30 \mathrm{~mA} / \mathrm{cm}^{2}$ (which corresponds to $1.26 \mathrm{~V}$ OER potential determined vs. RHE) for all experiments that have been carried out with Ni42 WE and Pt CE with hematite-sulfuric acid suspensions (30-40 g $\left.\mathrm{Fe}_{2} \mathrm{O}_{3}, 125 \mathrm{~mL} 0.5 \mathrm{M} \mathrm{H}_{2} \mathrm{SO}_{4}\right)$.

In general, in water electrolysis a potential of around $1.26 \mathrm{~V}$ vs. RHE (which corresponds to an overpotential of $\sim 30 \mathrm{mV}$ ) necessary to result in an (anodic) current density of $30 \mathrm{~mA} / \mathrm{cm}^{2}$ determined in $0.5 \mathrm{M}$ sulfuric acid is currently unparalleled. A similar low potential for OER was derived from lithiated Co-based steel ${ }^{34}$. However, we determined this potential at substantially lower current density $\left(10 \mathrm{~mA} / \mathrm{cm}^{2}\right)$ and in neutral regime. In addition, lithiated steel exhibited this outstanding activity only for a short time ${ }^{34}$. We recently determined for the anodic half-cell reaction of water electrolysis in sulfuric acid realized upon stainless steels overpotentials that are at least 25 times higher ${ }^{17,18}$. In view of very recently ${ }^{35,36}$ reported results on the field of acid-based electrocatalysis these current-voltage relationships are absolute unique. Yang et al. reported on perovskite structured $\mathrm{SrlrO}_{3}$ exhibiting a potential of $1.52 \mathrm{~V}$ vs. RHE $\left(\eta^{\sim} 300 \mathrm{mV}\right)$ for $10 \mathrm{~mA} / \mathrm{cm}^{2}$ current density in $0.5 \mathrm{M} \mathrm{H}_{2} \mathrm{SO}_{4}{ }^{35}$. Zhou et al. investigated Rutile- type oxides of the Mn-Sb-O system and found similar activity as found for $\mathrm{IrO}_{2}$ (onset of $\mathrm{OER}$ at $\eta^{\sim} 300 \mathrm{mV}$ ) in $1 \mathrm{M} \mathrm{H}_{2} \mathrm{SO}_{4}$ but with improved stability $^{37}$. As mentioned the overpotential derived from Ir-Sr-O based systems was found to be at least 15 times higher than the one we present in this contribution ${ }^{26}$.

Tafel measurements were carried out with weak IR correction (see experimental details) in the upper current density region $\left(>20 \mathrm{~mA} / \mathrm{cm}^{2}\right)$ since this current range is closer to industrial conditions (Figure 3a, 3b). The Tafel slope amounted to $188.7 \mathrm{mV} \mathrm{dec}^{-1}$ (Figure 3b). Compared to other works this value seems to be quite high. Since the Tafel slopes were derived from CP data recorded at higher current 
density they do not simply cover charge transfer kinetic effects but are likely influenced by mass transfer limitations.

a)

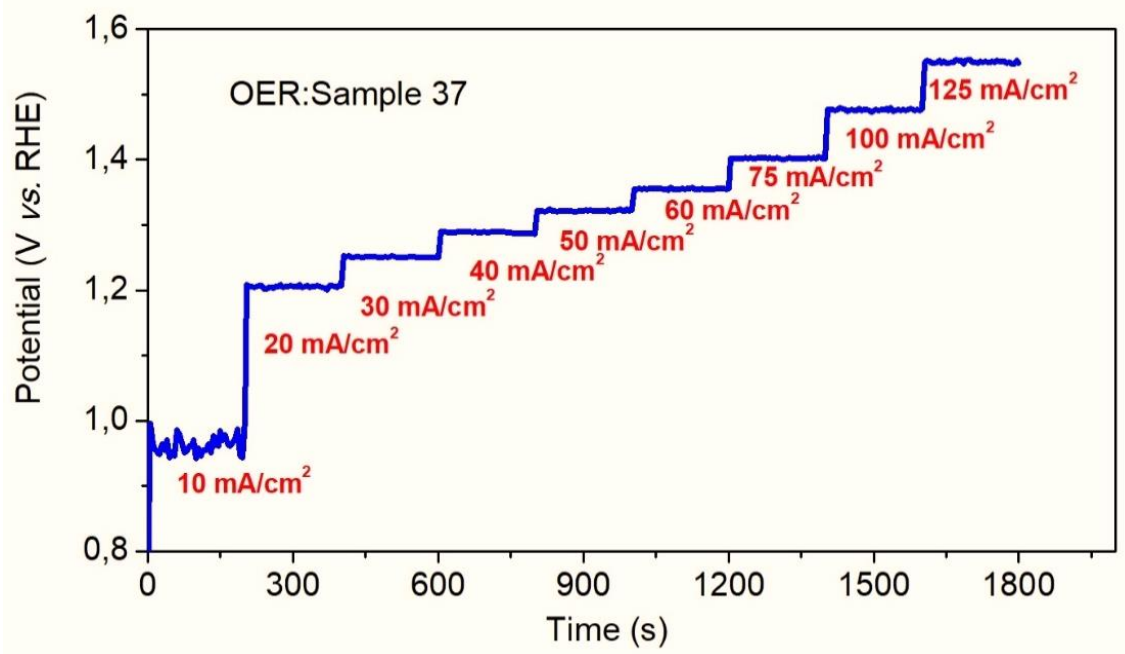

b)

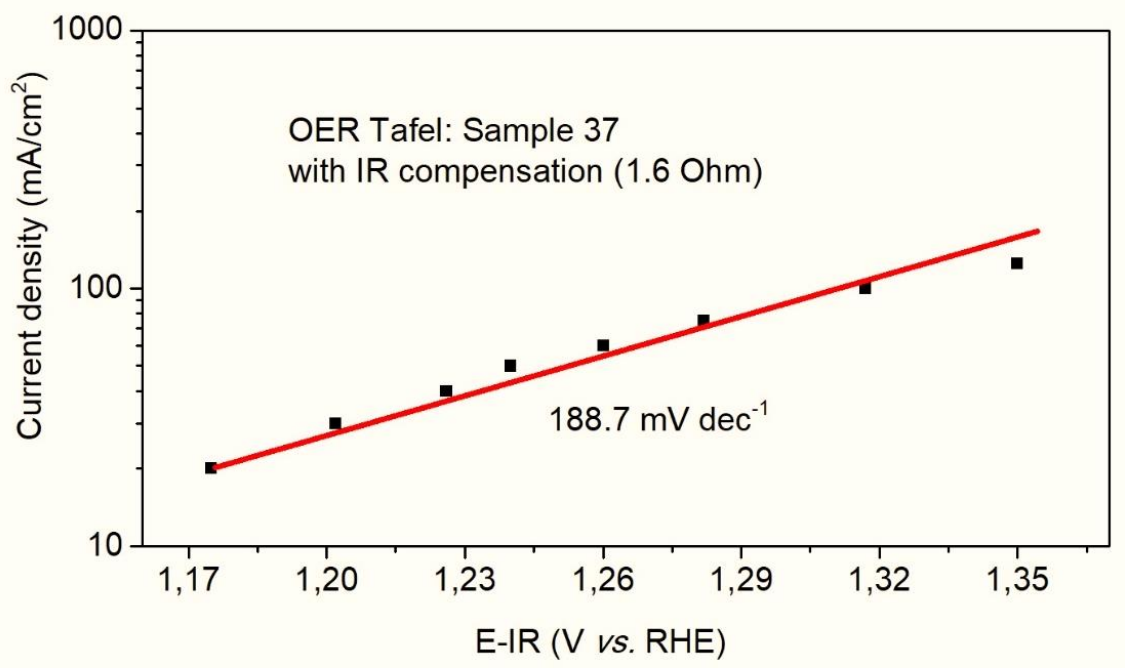

Figure 3. The voltage-current dependence of sample 37 determined under steady state conditions. Electrode area: $2 \mathrm{~cm}^{2}$. (a) Chronopotentiometry measurement showing a step wise increase of the current density; No IR compensation of the data. (b) Tafel plot based on 200 second chronopotentiometry scans at current densities 20, 30, 40,50,60,75, 100 and $125 \mathrm{~mA} / \mathrm{cm}^{2}$. IR-compensation of the data based on $57 \%$ of the solution resistance $(2.6 \mathrm{Ohm})$.

A low potential of the working electrode in OER electrocatalysiscan be sees as the first indication of a highly efficiently promoted OER, but as long as it not clear, up to what extent anodic current is actually used for the (formal) discharge of $\mathrm{O}^{2-}$ to molecular oxygen, it is all other than solid evidence. 
Years ago we found astonishingly low overpotentials derived from chronopotentiometry measurements carried out with super duplex steel X2CrNiMoCuWN25-7-4 with a chromium content up to $26 \mathrm{wt}$.\% in $0.05 \mathrm{M} \mathrm{H}_{2} \mathrm{SO}_{4}$. As can be taken from Figure 4a the overpotential for anodic water splitting amounted to $\sim 250 \mathrm{mV}$ at $10 \mathrm{~mA} / \mathrm{cm}^{2}$ current density in $0.05 \mathrm{M} \mathrm{H}_{2} \mathrm{SO}_{4}$ which, in principal is a fantastic low value implying an outstanding OER activity.

However, the charge to oxygen conversion rate (Faradaic efficiency) was only 15.7\% (Figure 4b) , i.e. the biggest part of the current obviously supports non-OER-based processes like e.g. oxidation of the catalyst itself which is understandable keeping in mind that untreated steel has been studied. This poor Faradaic efficiency however prohibits a further investigation of this steel type.
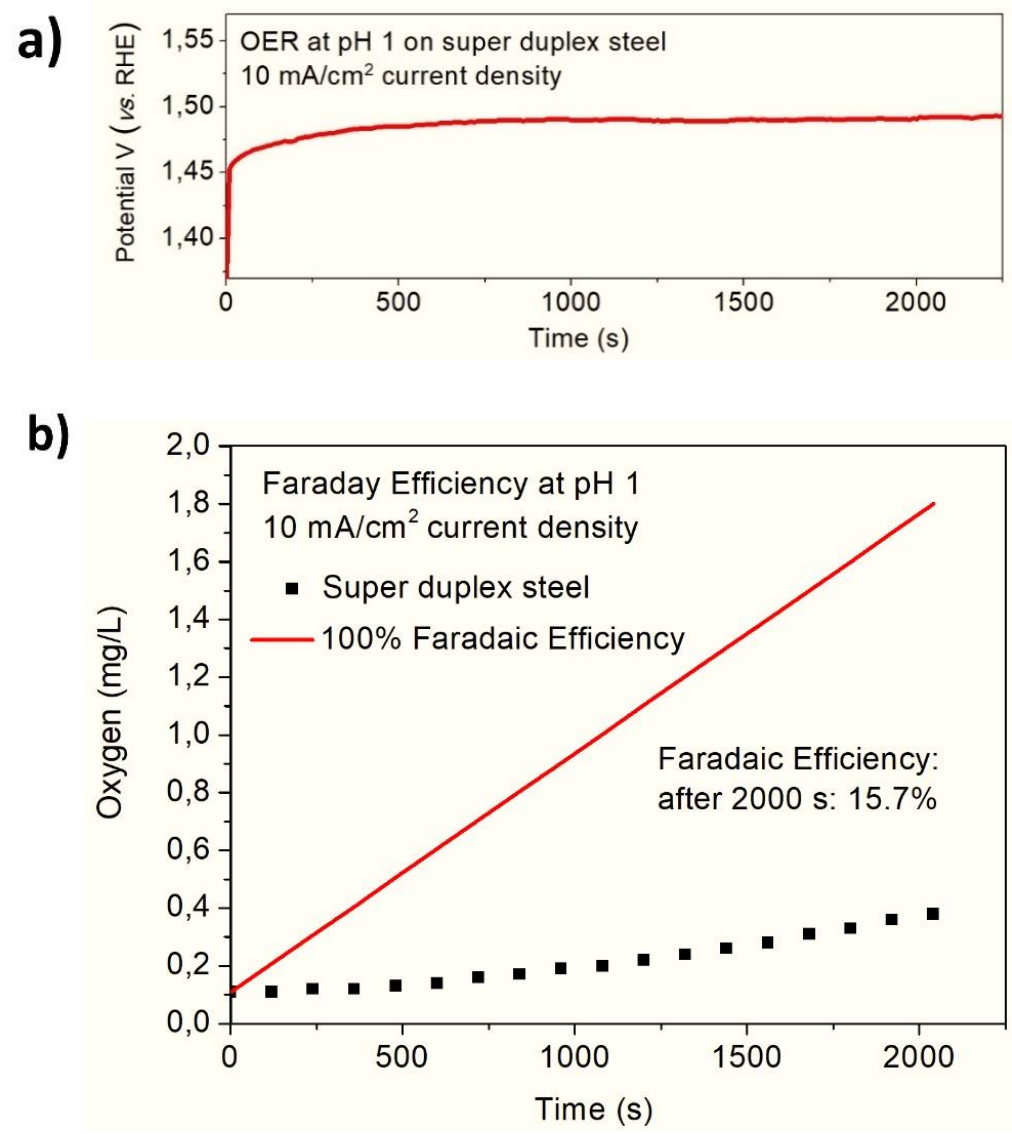

Figure 4. The charge to oxygen conversion rate (Faradaic efficiency) whilst oxygen evolution on untreated super duplex steel at constant current density of $10 \mathrm{~mA} / \mathrm{cm}^{2}$ in $0.05 \mathrm{M} \mathrm{H}_{2} \mathrm{SO}_{4}$. (a) Corresponding Chronopotentiometry measurement. (b) Correlation of oxygen evolution (black dotted curve) with the charge passed through the electrode system (the red line corresponds to $100 \%$ Faradaic efficiency). 
In contrary, OER based electrolysis performed with $\mathrm{Ni42}$ as WE and Pt as $\mathrm{CE}$ using $\mathrm{Fe}_{2} \mathrm{O}_{3}$ suspended in sulfuric acid as electrolyte exhibited a very good Faradaic efficiency (Figures 5).

The Faradaic efficiency was determined for the OER on sample 22 under steady state conditions at a constant current density of $30 \mathrm{~mA} / \mathrm{cm}^{2}$ after two different operation times within the "low overpotential region" of a typical CP plot (Figure 5a) thus after two steps of current protocol I (0.3 A and 0.15 A step) when the OER potential reached a value of $\sim 1.26$ V vs. RHE (Figure 5a). The Faradaic efficiency amounted to $94.1 \%, 92.2 \%$ respectively after $\sim 26000 \mathrm{~s}$ and $\sim 56000 \mathrm{~s}$ of operation (Figure 5b). To further confirm that the detected oxygen has been produced by the electrochemical watersplitting half reaction, we additionally monitored the dissolved oxygen in the electrolyte after the electrolysis cell was disconnected from the power source. No significant change of the oxygen concentration was detected within a measuring period of $550 \mathrm{~s}$ which indicates that no oxygen flows into the measuring cell from the external environment (Figure S28).

It should be mentioned at this point that a current density of $30 \mathrm{~mA} / \mathrm{cm}^{2}$ at which this almost quantitative charge to oxygen conversion rate was determined, is substantially higher than the one chosen by us in earlier experiments or by other groups. Typically, the experimentally determined Faradaic efficiency for the OER on electrocatalysts was found to be lower at higher current densities $^{38}$. This method of determination is based on changes of the content of dissolved oxygen (in between approximately 0 and $4 \mathrm{mg} / \mathrm{L}$ ) in the electrolyte whilst chronopotentiometry measurements (Figure 5c, Supporting information, pages 2-3). 
a)

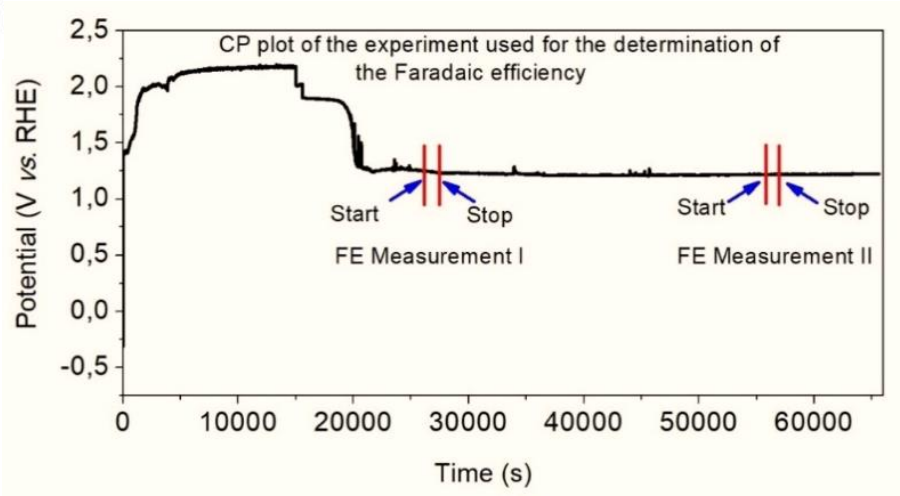

b)

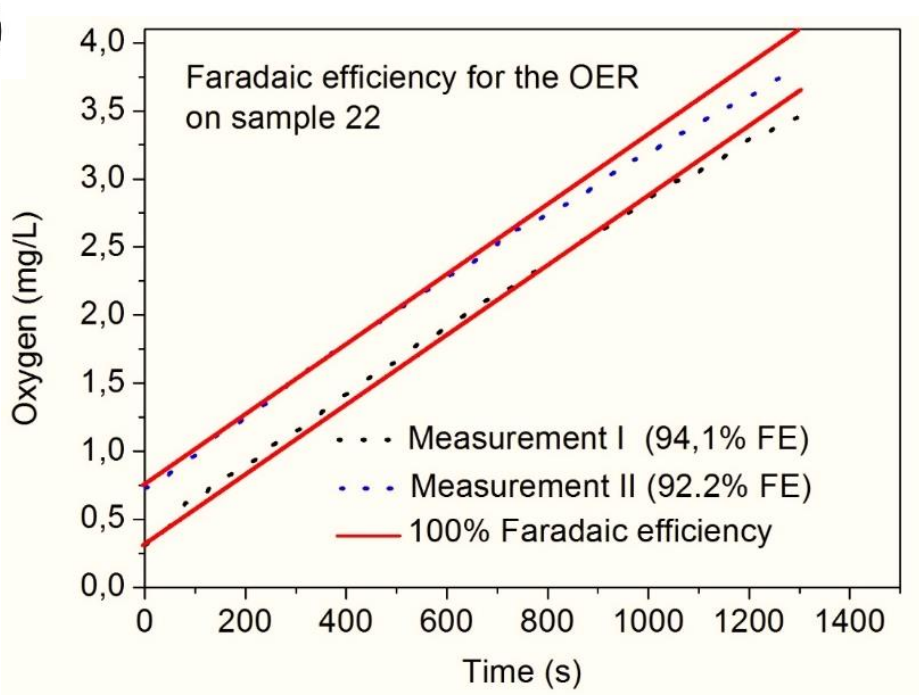

c)

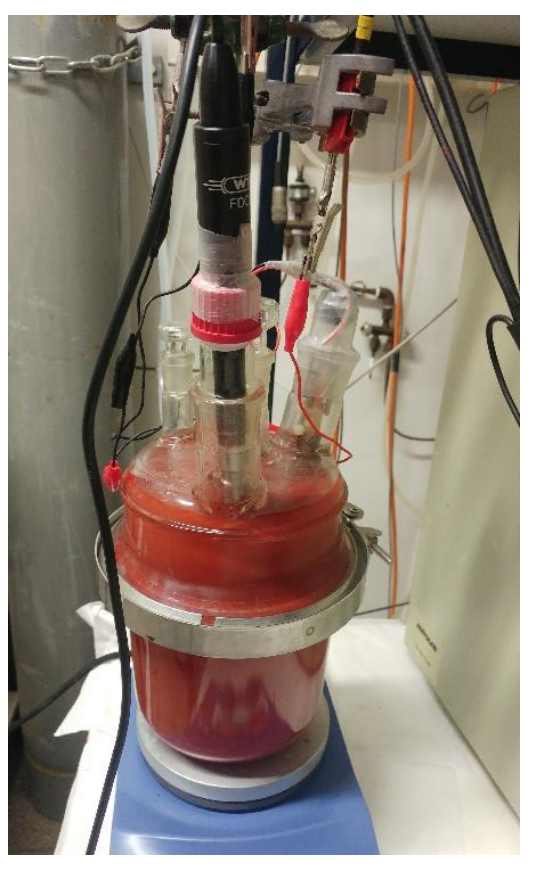

Figure 5. Faraday efficiency measurements of OER on a Ni42 (sample 22) in sulfuric acid/ $/ \mathrm{Fe}_{2} \mathrm{O}_{3}$ suspension whilst chronopotentiometric measurements at $30 \mathrm{~mA} / \mathrm{cm}^{2}$. Electrode area: $2 \mathrm{~cm}^{2}$.

(a) Chronopotentiometry measurement performed with sample 22 in $0.5 \mathrm{M} \mathrm{H}_{2} \mathrm{SO}_{4}$ at current densities of $150 \mathrm{~mA} / \mathrm{cm}^{2}, 75 \mathrm{~mA} / \mathrm{cm}^{2}$ and $30 \mathrm{~mA} / \mathrm{cm}^{2}$. The areas where the FE measurements begin and end are highlighted. (b) Correlation of oxygen evolution (black dotted curve: measurement 1; blue dotted curve: measurement 2) with the charge passed through the electrode system (the red line corresponds to $100 \%$ Faradaic efficiency). Amount of the electrolyte: $1.931 \mathrm{~L}$; Start value of dissolved oxygen: 0.31 $\mathrm{mg} / \mathrm{L}$ (experiment 1); Start value of dissolved oxygen: $0.73 \mathrm{mg} / \mathrm{L}$ (experiment 2). End value of dissolved oxygen $(t=1300 \mathrm{~s}): 3.46 \mathrm{mg} \mathrm{L}$ (experiment 1); end value of dissolved oxygen ( $t=1300 \mathrm{~s}): 3.82 \mathrm{mg} \mathrm{L}$ (experiment 2). Line equation (exp. 1): $y=0.0026 x+0.31$; line equation (exp. 2): $y=0.0026 x+0.73$ with $\mathrm{y}=$ oxygen concentration according to $\mathrm{FE}=100 \%$ and $\mathrm{x}=$ run time. Faradaic efficiency of the OER after 1300 s runtime: $94.1 \%$ (experiment 1); $92.2 \%$ (experiment 2). (c) Photo of the set-up. 
In order to further verify the data, we have chosen an additional, different approach that ensures separation of the electrodes and enables separate collection of the generated oxygen and hydrogen gas when using a special electrolysis cell (Figures 6a and 6b, Table S2; SI pages 2-3). The OER efficiency amounted to 89.6-95\%. The HER efficiency turned out to be somewhat lower (73.9-83.6\%). We also checked the suitability of a Nafion 212 membrane (SI, pages 3-4, Figure S29) and a glass filter plate to separate the anode and cathode compartment. Neither of the approaches was found to be useful either due to high cell voltage (glass filter plate) or because of short lifetime of the membrane which was blocked by the particles or mechanically affected due to the particles in combination with high stirring speed.

a)

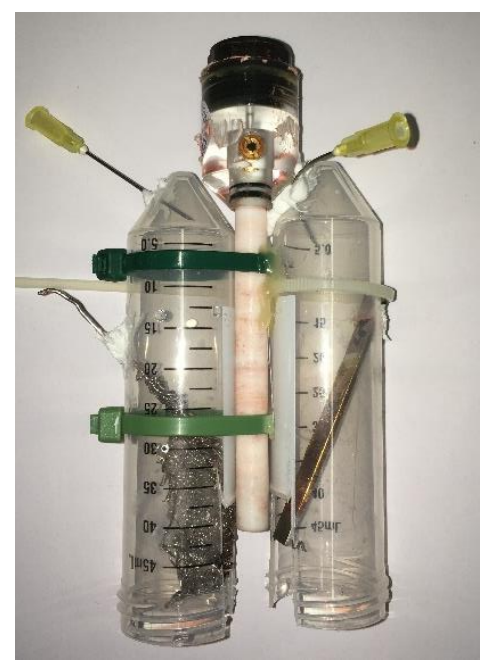

b)

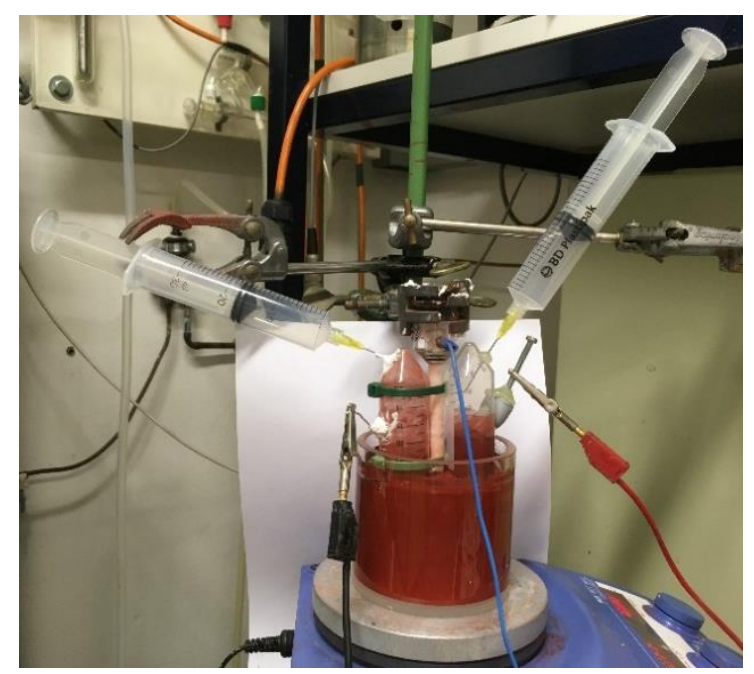

Figure 6a. Photo of the arrangement of the steel working electrode (to the right) and the platinum counter electrode (to the left) both covered by plastic cartridges. The reversible hydrogen electrode is placed in between CE and WE. 6b. Photo of the set up used for determining the Faradaic efficiency for the HER and the OER in sulfuric acid/hematite suspension (sample 39). Current density: $30 \mathrm{~mA} / \mathrm{cm}^{2}$; $E(O E R)=1.26$ V vs. RHE; Cell voltage: 1,60 V. HER and OER efficiency values see Table S2.

In total 13 experiments have been carried out which aimed to assess the long-term stability of the electrolysis setup against the evolution of oxygen (samples 26-31; 33-40) in $0.05 \mathrm{M} \mathrm{H}_{2} \mathrm{SO}_{4}$ or $0.5 \mathrm{M}$ 
$\mathrm{H}_{2} \mathrm{SO}_{4}$ (sample 37-40). Ni42 steel was used as WE and CE for all these experiments. These experiments were performed after carrying out the activation step (current protocol I) and consisted of a CP measurement (current protocol II) at constant current density of $10 \mathrm{~mA} / \mathrm{cm}^{2}\left(0.05 \mathrm{M} \mathrm{H}_{2} \mathrm{SO}_{4}\right)$ or $30 \mathrm{~mA} / \mathrm{cm}^{2}\left(0.5 \mathrm{M} \mathrm{H}_{2} \mathrm{SO}_{4}\right)$ with duration in between $78680 \mathrm{~s}$ (sample 27) and $529430 \mathrm{~s}$ (sample 36) as can be taken from Table S1. Two different approaches were used to test the long-term behavior. The sample series 26-31+33-36 were derived from applying a second current protocol in a freshly prepared "mild" hematite/sulfuric acid suspension with a very low amount of hematite (between 2.7 $\mathrm{g}$ and $7 \mathrm{~g}$ ) suspended in $125 \mathrm{~mL}$ of diluted sulfuric acid (0.05 M) see Table S1. This strategy led to sufficiently low potentials required to ensure a current density of $10 \mathrm{~mA} / \mathrm{cm}^{2}$ (Figure S30). However, the potential derived from CP measurements was found to be unstable and fluctuating between high and low values (Figure S30). The long term OER performance of samples 37-40 have been checked after cleaning and determining the weight of the Ni42 electrodes without replacement of the electrolyte, i.e. the concentration of $\mathrm{Fe}_{2} \mathrm{O}_{3}$ in sulfuric acid was substantially higher ( $35 \mathrm{~g}$ in 125 $\mathrm{mL} \mathrm{H}_{2} \mathrm{SO}_{4}$ ). A stable potential (averaged $1.26 \mathrm{~V}$ vs. $\mathrm{RHE}$ ) thus very close to the Standard Nernst potential of the water oxidation reaction can be derived from all the CP measurements made in this way (Figure 7).

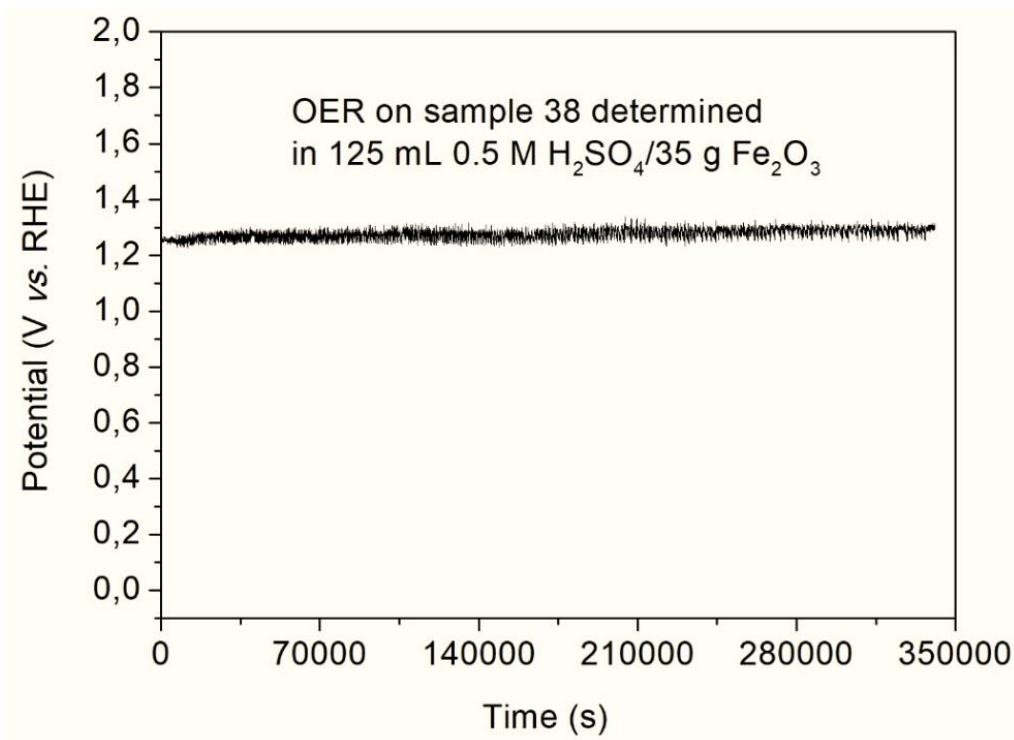

Figure 7. Current-voltage behavior of sample 38 determined in sulfuric acid/hematite suspension. Average potential: $1.26 \mathrm{~V}$ vs. RHE. 
An extremely low overpotential for the OER in combination with a sufficient conversion of electrical energy into molecular oxygen are key features of an electrocatalyst according to the prior art. However, In particular, if water cleavage at low pH is desired, there is another enormous challenge for an OER electrocatalyst: the threatening dissolution upon application of positive potentials which attracts a number of negative consequences like e.g. an increase in overpotential due to increasing current density (reduction of the active surface), high maintenance and repair costs, pollution of the electrolyte and so on. Although scientists have undertaken enormous research efforts to get this problem under control, to the best of our knowledge there does not exists a single paper that reports on electrocatalysts durably supporting OER in acidic regime. This assessment even captures noble element containing material like Ir-oxide, Ru-oxide or Ir-Ru-oxide ${ }^{26}$.

Thus, OER electrocatalysts that exhibit promising electrochemical characteristics in acidic regime still need to prove inertness towards mass loss that occurs when positive potentials are applied.

In addition to capturing the current-voltage characteristics, the mass deficit of the anode that occurs whilst long term usage as oxygen evolving electrode was determined. Again, the best results (samples 37-40) were obtained when, after completion of the activation step, the electrodes were washed and dried and, after determining the mass loss, were used as WE and CE in the same electrolyte to perform the long term performance test. Stirring was applied whilst long term electrolysis, however, the stirring rate was, in comparison with the one used during the activation procedure reduced from 4.5 to 3.0. The average duration of $\mathrm{CP}$ testing at $30 \mathrm{~mA} / \mathrm{cm}^{2}$ was $341000 \mathrm{~s}$ (almost $95 \mathrm{~h}$ ). The anodes lost (averaged) $30.1 \mathrm{mg}$ of mass upon exploitation as oxygen evolving electrode for $341000 \mathrm{~s}$ in $0.5 \mathrm{M} \mathrm{H}_{2} \mathrm{SO}_{4}$ at $30 \mathrm{~mA} / \mathrm{cm}^{2}$ (Table S1). This corresponds to a mass deficit of $22 \mu \mathrm{g} / \mathrm{mm}^{2}$ after $50000 \mathrm{~s}$ of $\mathrm{CP}$ at $30 \mathrm{~mA} / \mathrm{cm}^{2}$ current density which can be seen as an outstanding good outcome especially when taking into consideration the high current density of $30 \mathrm{~mA} / \mathrm{cm}^{2}$, the aggressive electrolyte with $\mathrm{pHO}$ and the fact that the electrodes solely consist of non-noble elements. 
The origin of the unusual high electrocatalytic OER activity-a proposed mechanism:

Since the ultralow OER potential of approximately 1.26 V vs. RHE (Sample 8; Figure 1a, black curve) which corresponds to an overpotential of approximately $30 \mathrm{mV}$ with respect to the oxidation of water molecules was not obtained when no hematite was added to the sulfuric acid electrolyte (Sample 1; Figure 1a, blue curve), the hematite can clearly be unmasked as the source of this unusual voltage-current behavior of this electrode-electrolyte $\left(\mathrm{H}_{2} \mathrm{SO}_{4} / \mathrm{Fe}_{2} \mathrm{O}_{3}\right.$ suspension) configuration. The question, why hematite suspended in sulfuric acid ensures enormously efficient and steadfast OER on Ni42 steel, i.e. the mechanism that hides behind it, will be discussed. The discussion is basically limited to effects due to the existence of hematite and iron ions and their interactions in the system.

Hematite added to $0.5 \mathrm{M}$ sulfuric acid does not solely end up in the formation of hematite particles suspended in clear electrolyte. It is known from literature that hematite can up to some extent be dissolved in $\mathrm{H}_{2} \mathrm{SO}_{4}{ }^{39}$. It turned out that stirring of $125 \mathrm{~mL} 0.5 \mathrm{M} \mathrm{H}_{2} \mathrm{SO}_{4}$ with $35 \mathrm{~g} \mathrm{Fe}_{2} \mathrm{O}_{3}$ for $50000 \mathrm{~s}$ (Table S1; sample 32) leads to the formation of a solution of $\mathrm{Fe}^{3+}$ ions based on $3.4 \mathrm{~g}$ of $\mathrm{Fe}_{2} \mathrm{O}_{3}$ found to be dissolved in sulfuric acid. To distinguish between the effect of free $\mathrm{Fe}^{3+}$ and suspended $\mathrm{Fe}_{2} \mathrm{O}_{3}$ particles on the OER properties of a $\mathrm{Ni} 42$ anode in acidic regime, the suspension achieved after $50000 \mathrm{~s}$ of stirring hematite in sulfuric acid ( $35 \mathrm{~g}$ hematite; $125 \mathrm{~mL} 0.5 \mathrm{M} \mathrm{H}_{2} \mathrm{SO}_{4}$ ) was centrifuged and OER electrocatalysis has been carried out with the clear supernatant solution (Sample 32, Figure 8). 


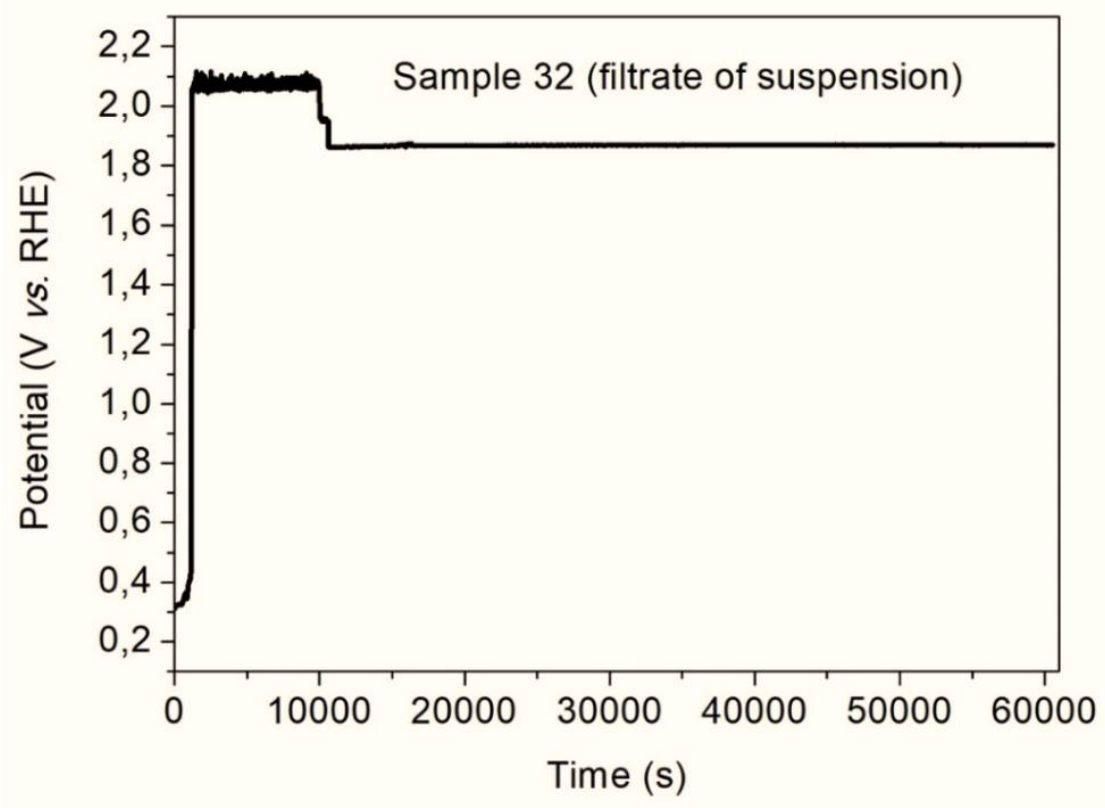

Figure 8. Chronopotentiometry measurement of Ni42 electrode (WE) upon usage of Ni42 as CE at constant current density of $150 \mathrm{~mA} / \mathrm{cm}^{2}, 75 \mathrm{~mA} \mathrm{~mA} / \mathrm{cm}^{2}$ and $30 \mathrm{~mA} / \mathrm{cm}^{2}$. Preparation of the electrolyte: $125 \mathrm{~mL} 0.5 \mathrm{M} \mathrm{H}_{2} \mathrm{SO}_{4}$ was stirred with $35 \mathrm{~g} \mathrm{Fe}_{2} \mathrm{O}_{3}$ for $50000 \mathrm{~s}$. The suspension was filtered and the filtrate was used as the electrolyte. The electrolyte contains about $3.4 \mathrm{~g} \mathrm{Fe}_{2} \mathrm{O}_{3}$ dissolved in $125 \mathrm{~mL} 0.5 \mathrm{M} \mathrm{H}_{2} \mathrm{SO}_{4}$. Stirring rate: 4.5.

The CP results of sample 32 are consistently comparable to those of sample 1 (Figures $1 \mathrm{a}$, blue curve) derived from electrolysis without adding solid $\mathrm{Fe}_{2} \mathrm{O}_{3}$. This clearly emphasizes that the sole presence of $\mathrm{Fe}^{3+}$ ions cannot account for the unusual OER behavior of $\mathrm{Ni} 42$ steel in sulfuric acid. Based on these results, and given the fact that the formation of free (dissolved) $\mathrm{Fe}^{3+}$ ions takes a considerable time after mixing of hematite with acid, the decrease of the potential (to $\mathrm{E}^{\sim} 1.26 \mathrm{~V} v \mathrm{vs}$. RHE; Figures 1a-black curve, S2, S3, S5-S27) that takes place after e.g. 40000 s of OER (Figure 1a, black curve) to maintain an OER based current density of $30 \mathrm{~mA} / \mathrm{cm}^{2}$ is very likely due to a simultaneous presence of $\mathrm{Fe}_{2} \mathrm{O}_{3}$ particles and free dissolved $\mathrm{Fe}^{3+}$ ions.

As can be taken from Figures S2, S3, S5-S27 displaying selected CP plots according to the experiments mentioned in Table S1, the time that lasts until the low potential has finally reached, critically 
depends on (i) the stirring rate and (ii) the amount of hematite. With a constant amount of hematite it was found that the activation process can be accelerated with more intense stirring (Figure 9a). At constant stirring speed, in turn, the desired voltage drop occurs earlier as the amount of hematite increases (Figure 9b).

a)

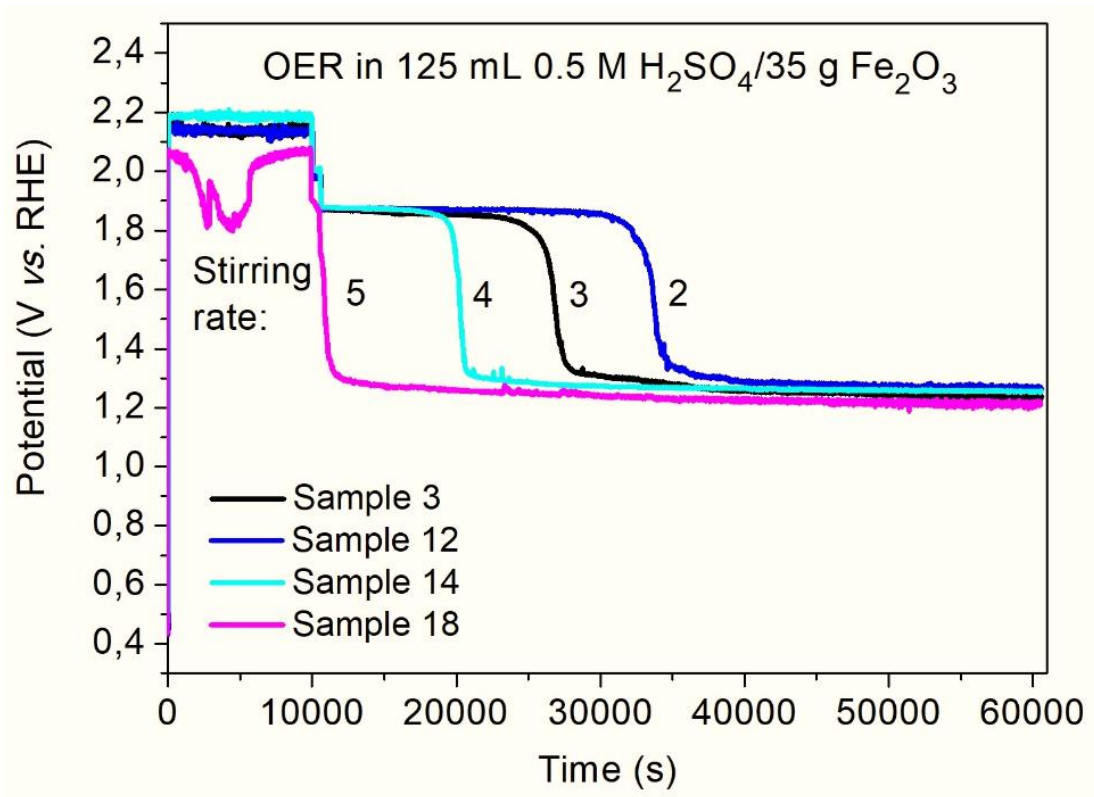

b)

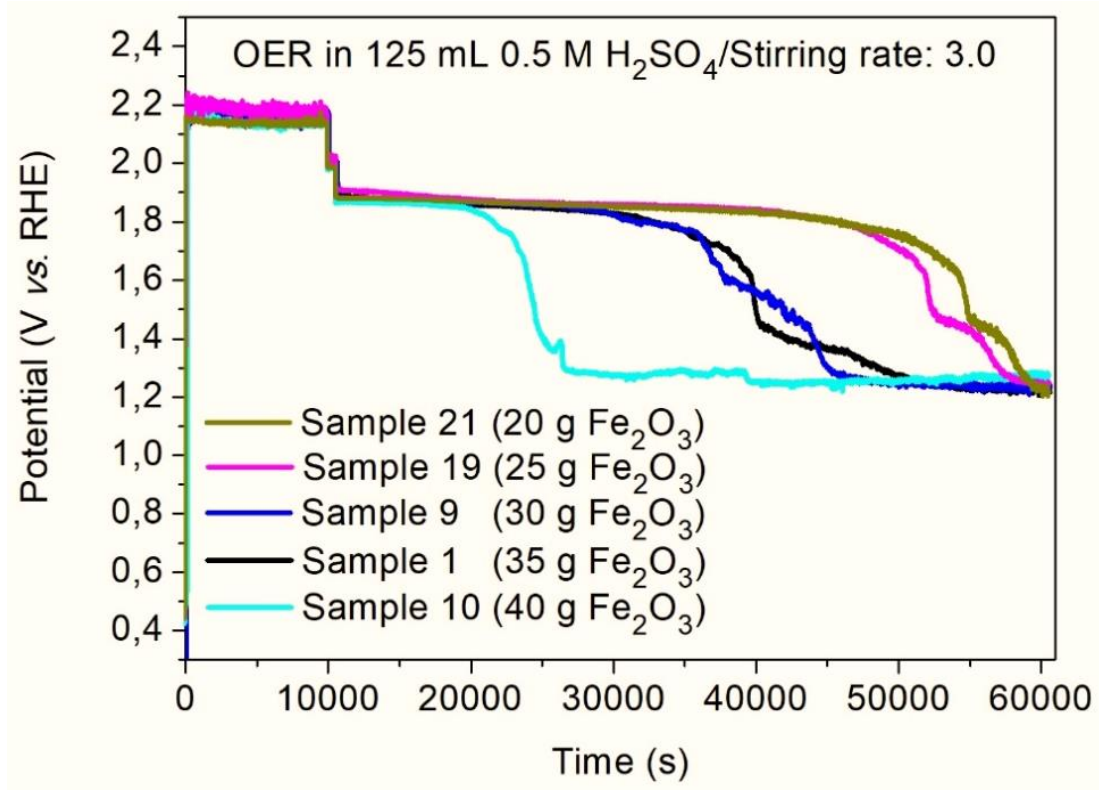

Figure 9. Influence of the stirring rate (top figure) and the amount of hematite (lower figure) on the voltage current behavior of a hematite sulfuric acid suspension at oxygen evolution conditions. Current protocol: 0.3 A-10000 s; 0.15 A-600s; 0.06 A-50000 s (See Table S1). Electrode area: 2 cm$^{2}$; Dimension of the stirring bar: $40 \times 8 \mathrm{~mm}$. A stirring rate of 1.0 corresponds to a speed of 100 per minute. 
Since both the amount of $\mathrm{Fe}_{2} \mathrm{O}_{3}$ and the stirring rate have a direct influence on the rate at which free $\mathrm{Fe}^{3+}$ ions are formed, or on the amount of iron oxide crystals present in the suspension, this result supports the assumption that the presence of free $\mathrm{Fe}^{3+}$ ions and solid $\mathrm{Fe}_{2} \mathrm{O}_{3}$ crystals play an important role with respect to the voltage/current behavior of an anode in $\mathrm{Fe}_{2} \mathrm{O}_{3} / \mathrm{H}_{2} \mathrm{SO}_{4}$ suspensions. Furthermore, it seems to be logical that $\mathrm{Fe}^{3+}$ will be reduced to $\mathrm{Fe}^{2+}$ through reaction with the cathode on which $\mathrm{H}_{2}$ evokes whilst water electrolysis. In order to find an experimental prove for this claim we investigated the electrolyte after completion of the electrolysis. The suspended solid was separated from the clear sulfuric acid by centrifugation. It turned out that the sulfuric acid, e.g. of samples $29,36,37,38,39$, and 46 contained a substantial amount of $\mathrm{Fe}^{2+}$ ions as was proven by testing with $\mathrm{K}_{3}[\mathrm{Fe}(\mathrm{CN}) 6]_{3}$ solution (1 wt.\% in water) leading to deep blue precipitation of Turnbull's blue which can be very well seen by eye (Figures S31 a, b, c, d, e, g). A direct dissolution of hematite in sulfuric acid does not lead to the formation of $\mathrm{Fe}^{2+}$ in solution. Sample 42 represents stirring of 125 $\mathrm{mL} 0.5 \mathrm{M} \mathrm{H}_{2} \mathrm{SO}_{4}$ with $35 \mathrm{~g}$ of hematite for $50000 \mathrm{~s}$ without applying any current. As already shown (sample 32), a considerable amount of hematite is dissolved in sulfuric acid (3.4 g, see Table S1) while stirring. The filtrate of the suspension ( $35 \mathrm{~g}$ hematite $/ 125 \mathrm{~mL} \mathrm{H}_{2} \mathrm{SO}_{4}$ ) stirring (current less) for 50000 $\mathrm{s}$ did indeed, as expected, not contain $\mathrm{Fe}^{2+}$ ions as can be taken from the brownish coloured solution without a Turnbull`s blue precipitation after adding $\mathrm{K}_{3}[\mathrm{Fe}(\mathrm{CN}) 6]_{3}$ (see Figure S31f). We assume that $\mathrm{Fe}^{2+}$ ions existing in the sulfuric acid have their origin in a cathodic reduction of $\mathrm{Fe}(\mathrm{III})$ that comes from dissolution of hematite. However, "direct dissolution" of the steel electrode in $\mathrm{H}_{2} \mathrm{SO}_{4}$ may also cause free $\mathrm{Fe}^{2+}$ ions. To exclude that $\mathrm{Fe}^{2+}$ has its origin in a dissolution of the iron content of steel in sulfuric acid (there is still a mass deficit when comparing the weight of the steel anode before and after carrying out electrocatalysis) we replaced in one of the experiments carried out with $\mathrm{Fe}_{2} \mathrm{O}_{3} / \mathrm{H}_{2} \mathrm{SO}_{4}$ suspension the steel anode by a graphite electrode and the $\mathrm{Ni} 42$ steel cathode by a platinum counter electrode (sample 43). Electrolysis was carried out as usual (Table S1) and the electrolyte was investigated. This set up exhibited a similar voltage current behaviour based on the final, constant potential (Figure 10) as was found with Ni42 steel used as WE and CE or when Ni42 
was used as WE and Pt as CE (Figure 1a, black curve) clearly underpinning that Ni42 electrodes are at least under these electrolysis conditions, suitable for the replacement of PGM electrodes but, however, are obviously not responsible for the sophisticating OER properties, obtained when a $\mathrm{Fe}_{2} \mathrm{O}_{3}$ /sulfuric acid mixture is used as electrolyte.

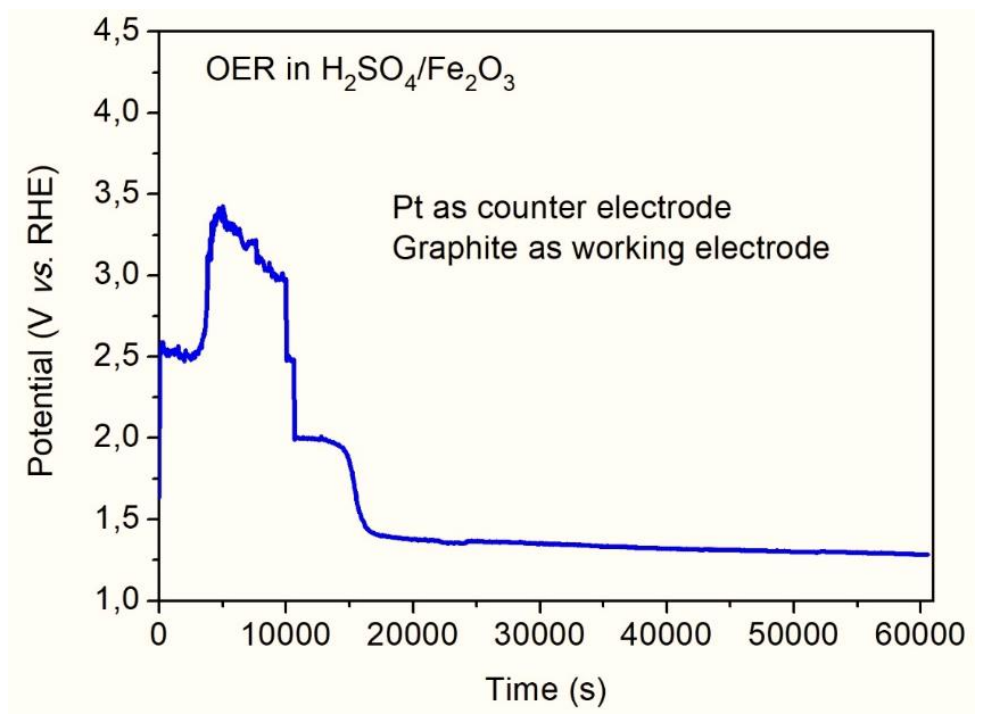

Figure 10. Chronopotentiometry measurement carried out with a $\mathrm{H}_{2} \mathrm{SO}_{4} / \mathrm{Fe}_{2} \mathrm{O}_{3}$ suspension $(125 \mathrm{~mL}$ $0.5 \mathrm{M} \mathrm{H}_{2} \mathrm{SO}_{4} ; 35 \mathrm{~g} \mathrm{Fe}_{2} \mathrm{O}_{3}$ ) upon usage of a platinum CE and a graphite WE. Current protocol I (See Table S1). Details see experimental part.

The clear sulfuric acid obtained after electrolysis of a hematite/sulfuric acid electrolyte upon exploitation of a Pt and a graphite electrode contained $\mathrm{Fe}^{2+}$, as evidenced by $\mathrm{K}_{3}\left[\mathrm{Fe}(\mathrm{CN})_{6}\right]$, which showed a Turnbulls Blue precipitation (Figure S32). This finding suggests that indeed dissolution of hematite and further reduction of $\mathrm{Fe}^{3+}$ to $\mathrm{Fe}^{2+}$ takes place in the electrolysis reaction of a hematite $/ \mathrm{H}_{2} \mathrm{SO}_{4}$ suspension. Thus, the outcome from all the experiments mentioned so far can be reasonably interpreted this way: The simultaneous presence of free $\mathrm{Fe}^{2+} / \mathrm{Fe}^{3+}$ and suspended hematite particles plays a dominating role for the extraordinary electrocatalytic activity of the 
electrode/electrolyte system. We determined the concentration of $\mathrm{Fe}^{2+} / \mathrm{Fe}^{3+}$ and the amount of suspended oxide particles in the electrolyte subsequently after the potential to ensure an OER-based current density of $30 \mathrm{~mA} / \mathrm{cm}^{2}$ dropped down to around $1.26 \mathrm{~V}$ vs. RHE, i.e. after completion of the activation, upon redox titration $\left(\mathrm{C}\left(\mathrm{Fe}^{2+}\right)\right)$ and gravimetric analysis (total amount of $\mathrm{Fe}$ ). It turned out that the "active" electrolyte consists of around $0.0036 \mathrm{Mol} / \mathrm{L} \mathrm{Fe}(\mathrm{II}) ; 0.29 \mathrm{Mol} / \mathrm{L} \mathrm{Fe}(\mathrm{III}) ; 32 \mathrm{~g}$ (undissolved) $\mathrm{Fe}_{2} \mathrm{O}_{3}$ particles and $125 \mathrm{~mL} 0.5 \mathrm{M} \mathrm{H}_{2} \mathrm{SO}_{4}$ (See Table S3, SI).

As a result, the existence of free $\mathrm{Fe}^{2+} / \mathrm{Fe}^{3+}$ plus $\mathrm{Fe}_{2} \mathrm{O}_{3}$ suspended in $0.5 \mathrm{M} \mathrm{H}_{2} \mathrm{SO}_{4}$ (sample 44) right at the beginning of the chronopotentiometry experiment should lead to sufficient low overpotentials. In fact, adding $1.5 \mathrm{~g} \mathrm{Fe}$ (III) $\mathrm{SO}_{4}+0,5 \mathrm{~g} \mathrm{Fe}(\mathrm{II}) \mathrm{SO}_{4}+30 \mathrm{~g}$ hematite to $125 \mathrm{~mL} 0.5 \mathrm{M} \mathrm{H}_{2} \mathrm{SO}_{4}$ led to a potential of $1.25 \mathrm{~V}$ vs. RHE required to ensure $30 \mathrm{~mA} / \mathrm{cm}^{2}$ current density (Figure S33). However $1000 \mathrm{~s}$ after mixing of the compounds (before completion of the current protocol I according to Table S1) this sample exhibited only weak OER and HER efficiency in the range between 13 and 15\% (HER) and $16-17 \%$ (OER). It therefore seems to be very difficult to adjust the necessary $\mathrm{Fe}^{2+} / \mathrm{Fe}^{3+}$ concentration by adding soluble Fe(II)/Fe(III) salts. In addition, the interaction of free ions with suspended particles caused by an "electrochemical induction" (current protocol I) is the crucial prerequisite for advanced OER / HER properties. If the concentration of free $\mathrm{Fe}^{2+} / \mathrm{Fe}^{3+}$ is too high, oxygen evolution is suppressed and simple migration of $\mathrm{Fe}^{3+}$ to the cathode followed by reduction to $\mathrm{Fe}^{2+}$ and migration of $\mathrm{Fe}^{2+}$ to the anode followed by oxidation to $\mathrm{Fe}^{3+}$ are the dominating processes leading to relative high currents at low potential. For example, the electrolysis of $0.5 \mathrm{M} \mathrm{H}_{2} \mathrm{SO}_{4}$ containing $\mathrm{Fe}^{3+}$ ions $\left(\mathrm{c}=0.16 \mathrm{~mol} / \mathrm{L}\right.$ ) at $30 \mathrm{~mA} / \mathrm{cm}^{2}$ (sample 41) over the entire course of the $\mathrm{CP}$ curve showed a potential below the standard Nernst Potential for water oxidation (1.229 V vs. RHE). As a result, no oxygen bubbles formation can be seen of on the surface of the anode (Figure S34). These experimental findings suggest that iron ions, which are somehow trapped by Fe oxide-based particles, play the key role in promoting OER in the electrolysis of a $\mathrm{Fe}_{2} \mathrm{O}_{3} / \mathrm{H}_{2} \mathrm{SO}_{4}$ suspension. The following equation applies to iron in oxidation state +2 in aqueous solution:

$\left[\mathrm{Fe}\left(\mathrm{H}_{2} \mathrm{O}\right)_{6}\right]^{2+}+\mathrm{H}_{2} \mathrm{O} \leftrightarrow\left[\mathrm{Fe}\left(\mathrm{H}_{2} \mathrm{O}\right)_{5} \mathrm{OH}\right]^{+}+\mathrm{H}_{3} \mathrm{O}^{+}$ 
In principal we can define a reaction between these aquo complexes and solid $\mathrm{Fe}_{2} \mathrm{O}_{3}$ finally end up in the formation of a mixed valence iron oxide " $\mathrm{Fe}_{3} \mathrm{O}_{4}$ ":

$\left[\mathrm{Fe}\left(\mathrm{H}_{2} \mathrm{O}\right)_{5} \mathrm{OH}\right]^{+}+\mathrm{Fe}_{2} \mathrm{O}_{3} \rightarrow \mathrm{Fe}_{3} \mathrm{O}_{4}+4 \mathrm{H}_{2} \mathrm{O}+\mathrm{H}_{3} \mathrm{O}^{+}$

$\left[\mathrm{Fe}\left(\mathrm{H}_{2} \mathrm{O}\right)_{6}\right]^{2+}+\mathrm{Fe}_{2} \mathrm{O}_{3} \rightarrow \mathrm{Fe}_{3} \mathrm{O}_{4}+2 \mathrm{H}_{3} \mathrm{O}^{+}+3 \mathrm{H}_{2} \mathrm{O}$

This is generally not as unusual as it seems, since it is known that $\mathrm{Fe}_{3} \mathrm{O}_{4}$ is formed by $\mathrm{Fe}^{3+} / \mathrm{Fe}^{2+}$ mixtures in aqueous solution at low temperature ${ }^{40}$. In addition, a reduction of $\mathrm{Fe}_{2} \mathrm{O}_{3}$ to $\mathrm{Fe}_{3} \mathrm{O}_{4}$ under wet-electrochemical conditions is currently being discussed in some articles ${ }^{41}$. However, a direct interaction of free $\mathrm{Fe}^{2+}$ with free $\mathrm{Fe}^{3+}$ in aqueous solution (without the contribution of $\mathrm{Fe}_{2} \mathrm{O}_{3}$ ) which leads to $\mathrm{Fe}_{3} \mathrm{O}_{4}$, is very unlikely since, to our knowledge, this has not been achieved in acidic regimes $^{42}$.

Equation (3)' involving a mechano-electrochemical step can serve as a possible alternative to equation (2) and (3) which seems more likely to exist ${ }^{42}$.

$3 \mathrm{Fe}_{2} \mathrm{O}_{3}+2 \mathrm{H}^{+}+2 \mathrm{e}^{-} \rightarrow 2 \mathrm{Fe}_{3} \mathrm{O}_{4}+\mathrm{H}_{2} \mathrm{O}(3)^{\prime}$

We furthermore assume that the mixed valence species $\mathrm{Fe}_{3} \mathrm{O}_{4}$ will be converted back, i.e. oxidized while touching the anode to $\mathrm{Fe}_{2} \mathrm{O}_{3}$ under release of $\mathrm{O}_{2}$ :

$\mathrm{Fe}_{3} \mathrm{O}_{4} \rightarrow \mathrm{Fe}_{2} \mathrm{O}_{3}+\mathrm{Fe}^{3+}+1 / 2 \mathrm{O}_{2}+3 \mathrm{e}^{-}$

As a result, the oxygen-evolving centers are likely to be on the oxide particles rather than on the electrode. In order to find a first indication of the correctness of this theory, we determined the consumption of hematite during the electrolysis. After $341,000 \mathrm{~s}$ of electrolysis at a current of $60 \mathrm{~mA}$ corresponding to $0.21 \mathrm{~mol}$ of electrons that passed through the electrolysis cell (sample 38), the solid residue $\left(\mathrm{Fe}_{2} \mathrm{O}_{3}\right)$ was $31.31 \mathrm{~g}$. As mentioned, a substantial portion of hematite ( $3.4 \mathrm{~g}$ of $35 \mathrm{~g}$ ) is simply dissolved upon stirring (Table S1, sample 32). Thus, the initial amount of $\mathrm{Fe}_{2} \mathrm{O}_{3}(35 \mathrm{~g}=0.22 \mathrm{~mol}$ ) was almost completely recovered.

However, this does not mean that the total amount of $\mathrm{Fe}_{2} \mathrm{O}_{3}$ is converted to $\mathrm{Fe}_{3} \mathrm{O}_{4}$ and vice versa. We rather assume that only a very small part of the material will be oxidized/reduced i.e. actually contributes to the catalysis reaction. It is therefore very likely that only the periphery of $\mathrm{Fe}_{2} \mathrm{O}_{3}$ 
particles suspended in sulfuric acid is covered by amorphous $\mathrm{Fe}_{3} \mathrm{O}_{4}{ }^{*} \mathrm{H}_{2} \mathrm{O}$ which is converted back to non-crystalline $\mathrm{Fe}_{2} \mathrm{O}_{3}$ which then covers the (predominantly) crystalline $\mathrm{Fe}_{2} \mathrm{O}_{3}$ particle.

It is important to note that the chemically bound oxygen in the hypothetically formulated active metal oxide species $\mathrm{Fe}_{3} \mathrm{O}_{4}$ comes from water molecules, i.e. the molecular oxygen released at the anode (equation 4) has its origin in water molecules (equation 1).

We therefore propose an electrocatalytically driven cyclic process involving molecular oxygen, water, and two different iron oxide species:

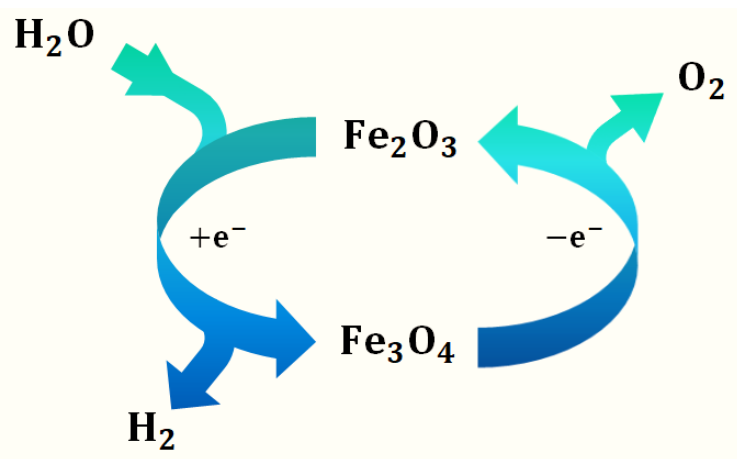

Scheme 1. A cyclic process ensures electrocatalytically initiated splitting of water mediated through two different oxide species.

This means that $\mathrm{Fe}_{3} \mathrm{O}_{4}$ particles formed on the cathode have to migrate to the anode in order to be converted into $\mathrm{Fe}_{2} \mathrm{O}_{3}$ particles, which in turn have to migrate to the cathode in order to maintain the circulation. In other words, migration of particles from the cathode compartment to the anode compartment and vice versa is required to maintain this cyclic process. This explains why cell designs that involve complete separation of the compartments from each other, e.g. by a Nafion membrane (PEM type electrolyzer) cannot lead to convincingly results.

In order to clarify why the water splitting reaction mediated by an electrocatalytically driven cycle with suspended iron oxide species is advantageous compared to the classic electrolysis of clear electrolytes, the energy balances for the assumed electrochemical half-cell reactions have to be drawn up. 
Two reactions are considered to take place simultaneously on the cathode, the mentioned reduction of $\mathrm{Fe}^{3+}$ to $\mathrm{Fe}^{2+}$ as well as HER:

Cathode: $\mathrm{Fe}^{3+}+3 \mathrm{e}^{-}+2 \mathrm{H}^{+} \rightarrow \mathrm{Fe}^{2+}+\mathrm{H}_{2}(5)$

Reaction 4 (page 24) describes the oxidation of the $\mathrm{Fe}_{3} \mathrm{O}_{4}$ particles to $\mathrm{Fe}_{2} \mathrm{O}_{3}$ upon release of oxygen and the overall reaction (gross) can be defined as:

$\mathrm{Fe}_{3} \mathrm{O}_{4}+2 \mathrm{H}^{+} \rightarrow \mathrm{Fe}_{2} \mathrm{O}_{3}+\mathrm{Fe}^{2+}+0.5 \mathrm{O}_{2}+\mathrm{H}_{2}(6)$

The standard reaction Gibbs energy $\Delta \mathrm{G}^{0}{ }_{\mathrm{R}}$ can be most conveniently calculated using the the standard Gibbs Energy of formation $\left(\Delta G_{f}^{0}\right)$ for all compounds involved ${ }^{43}$ :

$\mathrm{H}^{+}(0 \mathrm{~kJ} / \mathrm{mol}) ; \mathrm{Fe}^{2+}(-78.9 \mathrm{~kJ} / \mathrm{mol}) ; \mathrm{Fe}^{3+}(-4.7 \mathrm{~kJ} / \mathrm{mol}), \mathrm{H}_{2}(0 \mathrm{~kJ} / \mathrm{mol}) ; \mathrm{O}_{2}(0 \mathrm{~kJ} / \mathrm{mol}) ; \mathrm{Fe}_{2} \mathrm{O}_{3}(-742.2 \mathrm{~kJ} / \mathrm{mol}) ;$ $\mathrm{Fe}_{3} \mathrm{O}_{4}(-1015.4 \mathrm{~kJ} / \mathrm{mol})$. It should be noted that $\Delta \mathrm{G}_{\mathrm{f}}^{0}$ values of the iron oxide species belong to hematite and magnetite. The standard reaction Gibbs energy $\Delta \mathrm{G}_{\mathrm{R}}^{0}$ of the overall (gross) reaction amounts to $194.3 \mathrm{~kJ} / \mathrm{mol}$ which corresponds to a difference of the standard half-cell potentials $(\Delta \mathrm{E})$ of $0.67 \mathrm{~V}$.

The standard reaction Gibbs energy $\Delta \mathrm{G}_{\mathrm{R}}{ }_{\mathrm{R}}$ of the cathode half-cell reaction amounts to $-74,2 \mathrm{KJ} / \mathrm{mol}$ which corresponds to a standard half-cell potential of $+0.256 \mathrm{~V}$ vs. RHE. Given the difference of the standard half-cell potentials $(\Delta \mathrm{E}=0.67 \mathrm{~V})$ the thermodynamic half-cell potential of the oxygen evolution reaction is $+0.926 \mathrm{~V}$ vs. RHE which is significantly lower than the thermodynamic half-cell potential of the water oxidation reaction:

$\mathrm{H}_{2} \mathrm{O} \rightarrow 0.5 \mathrm{O}_{2}+2 \mathrm{H}^{+}+2 \mathrm{e}^{-} \mathrm{E}^{0}=+1.229 \mathrm{~V}$ vs. $\mathrm{RHE}$

This calculation is based on the Gibbs formation energies of the crystalline oxide species hematite and magnetite and we currently do not know whether these are the real species that are involved in the electrocatalytically driven cyclic process. This is probably the main source of error for an inaccurate prediction of the expected potential. Nevertheless, this explains the general sense of this transition metal -oxide based strategy to reduce the oxygen evolution reaction potential.

Taking the low temperature into account, it is unlikely that when $\mathrm{Fe}_{2} \mathrm{O}_{3}$ reacts with $\mathrm{Fe}^{2+}$ crystalline $\mathrm{Fe}_{3} \mathrm{O}_{4}$ (magnetite) and when $\mathrm{Fe}_{3} \mathrm{O}_{4}$ is oxidized, crystalline $\mathrm{Fe}_{2} \mathrm{O}_{3}$ is formed. In fact, we have found no 
evidence that magnetite forms in water electrolysis when a sulfuric acid/hematite mixture is used as the electrolyte. According to our own knowledge, even crystalline $\mathrm{Fe}_{3} \mathrm{O}_{4}$ (magnetite) shows considerable solubility in sulfuric acid $\left(0.16 \mathrm{~g}\right.$ in $\left.125 \mathrm{~mL} 0.5 \mathrm{M} \mathrm{H}_{2} \mathrm{SO}_{4}\right)$ based on our own findings. Therefore, even if crystalline $\mathrm{Fe}_{3} \mathrm{O}_{4}$ is temporarily formed by the reaction of hematite with $\mathrm{Fe}^{2+}$ its detection after electrolysis has ended in the solid residue of the electrolyte remains questionable. This is all the more true for amorphous $\mathrm{Fe}_{3} \mathrm{O}_{4}$, since it should have a much better solubility than crystalline $\mathrm{Fe}_{3} \mathrm{O}_{4}$. From literature is known, that amorphous $\mathrm{Fe}_{3} \mathrm{O}_{4}{ }^{*} \mathrm{H}_{2} \mathrm{O}$ and $\mathrm{Fe}_{2} \mathrm{O}_{3}{ }^{*} \mathrm{H}_{2} \mathrm{O}$ can actually be formed in aqueous solution at room temperature ${ }^{40}$. FTIR spectroscopy of the of the solid residue of the electrolyte of samples $26,29,30,33,37,38$, and 39 which were used for long term chronopotentiometry testing suggests that the originally used hematite remains unchanged after polarization measurements (Figures S35, S36). X-ray powder diffraction pattern of samples 37,38 and 39 do not differ from the one of hematite (ICSD 64599; Figure S37. The appearance of strong reflexes is not evidence of the absence of amorphous iron oxide phases ${ }^{44,45}$. The same samples (37-39) plus untreated hematite were subjected to a morphological examination via scanning electron microscopy (Figure S38). We have to say that the hematite starting material can be viewed as nanoscale. However, in case of all samples investigated, "square stone blocks" with an edge length in the range of $200 \mathrm{~nm}$ were obtained exhibiting no significant differences.

XPS spectroscopic investigation did not exhibit significant differences between the hematite reference sample and the solid residue of samples 26, 29, 30, 33 and 37 (Figure S39; Table S1). The Fe $2 p$ core level spectra are almost identical for all the samples and show a typical $\mathrm{Fe}^{3+}$ multiplet structrure. The peak positions of $\mathrm{Fe} 2 \mathrm{p}_{3 / 2}(711.5 \mathrm{eV})$, the $\mathrm{Fe}^{3+}$ charge transfer satellite $(719.3 \mathrm{eV})$ and Fe $2 p_{1 / 2}(724.8 \mathrm{eV})$ agree very well with the values found for $\alpha-\mathrm{Fe}_{2} \mathrm{O}_{3}$ quantum dots ${ }^{46}$. Ex Situ (electrooxidation-based) treatment has been successfully used to improve the electrocatalytic OER efficiency of Ni42 steel as was reported earlier ${ }^{17,47}$. Substantial amounts of metallic iron and nickel were found to exist in the surface of untreated Ni42 steel ${ }^{47}$. The content of metallic nickel and iron was 
suppressed by the electro-activation carried out in the alkaline range ${ }^{17,47}$. In particular Ni42 steel, to which positive potentials were applied, i.e. which was used as an anode for more than $332000 \mathrm{~s}$ ( 92 h) in the electrolysis of a hematite/sulfuric acid suspension (sample 37 ) at $30 \mathrm{~mA} / \mathrm{cm}^{2}$ current density, still shows a large proportion of metallic fractions of nickel and iron (Figure 11a-e; spot 2). This is absolutely unusual and unique for steel electrodes which have been used as anodes in water electrolysis in general. Pioneering studies by the groups of Hoare, Bard, Bockris, and several others ${ }^{48}$, 49, 50, showed that in case of metal electrodes no oxygen can be released from the surface if the corresponding metal oxide is not formed. Apart from the significantly increased metal content the high-resolution XPS (Fe 2p and Ni 2p) spectra of the Ni42 anode recorded after long term electrolysis (sample 37) did not substantially differ from XPS results derived from Ni42 electro-oxidized in alkaline regime as reported in one of our earlier contributions ${ }^{17}$.

We claim that e.g. $\mathrm{Ni}^{3+}$ ions in the surface of $\mathrm{Ni} 42$ (which have its origin in the oxidation of $\mathrm{Ni}^{0}$ upon strong oxidative potentials) are reduced by $\mathrm{Fe}_{3} \mathrm{O}_{4}$ particles in a mechano-chemical reaction to end up in $\mathrm{Ni}^{0}$, or in other words eq. (4) provides the electrons required to produce $\mathrm{Ni}$ metal via reduction of $\mathrm{Ni}(\mathrm{III})$ as seen by XPS spectroscopy.

Our finding (Figure 11) indeed indicates that oxygen does not come directly "out of the electrode", $i$. e. oxygen evolution centers are formed at the periphery of the particles at the moment the particles touch the electrode. Thus, the evolution of oxygen is mediated by the particle itself. As mass loss of the anode is known to occur especially when oxygen evolution is promoted on its surface this would explain the low weight loss of the anode whilst long term operation in water electrolysis (Table S1). 
a)

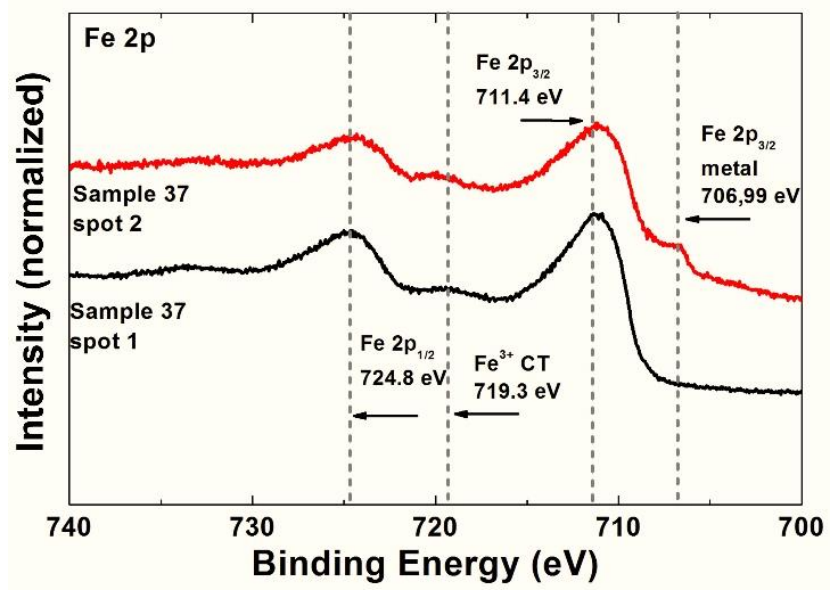

c)

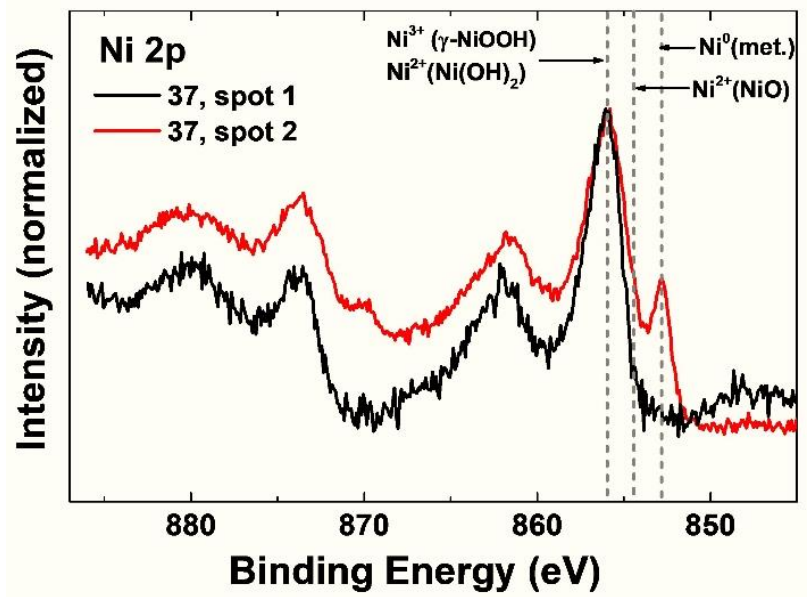

b)
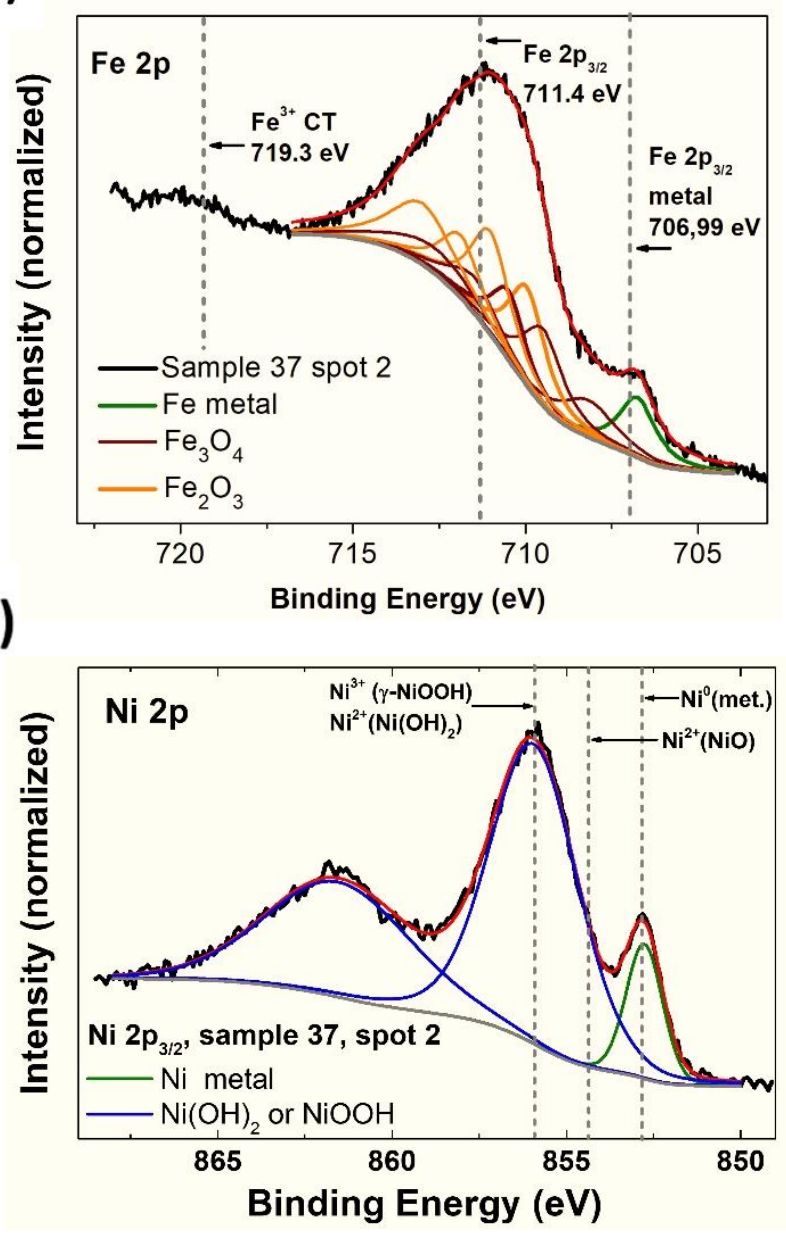

e)

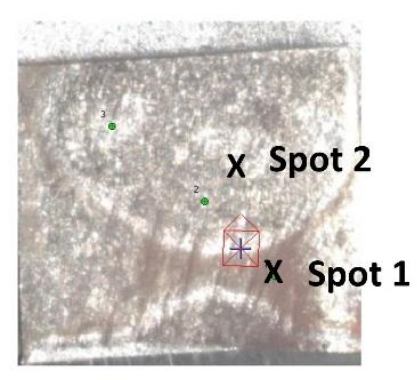

Figure 11. Results from the XPS investigation of the Ni42 electrode (sample 37) on two different spots. (a) High resolution XPS (Fe 2p) core level spectra. (b) Deconvoluted spectra; Fitting results: Ni $2 p_{3 / 2}$, position $852,8 \mathrm{eV}$; $\mathrm{Ni} 2 \mathrm{p}_{3 / 2}$, position $854,3 \mathrm{eV}$; Ni $2 \mathrm{p}_{3 / 2}$, position 855,9 eV. (c) High resolution XPS (Ni 2p) core level spectra. (d) Deconvoluted spectra; Fitting results: Fe $2 p_{3 / 2}$, position 706,99 eV; Fe $2 p_{3 / 2}$, position 711,4 eV; Binding energies of reference compounds are indicated by vertical lines as a guide to the eyes. (e) Photo of the sample surface showing the position of the two spots examined. 
Electron paramagnetic resonance (EPR) spectroscopy has been performed at $293 \mathrm{~K}$ and $15 \mathrm{~K}$ with (the solid residue of) samples 26, 29, 30, 33, 36, 37, 38 and 39 (Figure S40), and on reference samples, composed of $100 \%$ hematite (Reference 1 ) or $95 \%$ hematite/5\% magnetite (Reference 2 ). Noteworthy: The solid residue of samples 37-39 originated from the activation step (35 g of hematite in $125 \mathrm{~mL}$ of $0.5 \mathrm{M} \mathrm{H}_{2} \mathrm{SO}_{4}$; current protocol I) followed by long term electrolysis of the suspensionbased electrolyte at a current density of $30 \mathrm{~mA} / \mathrm{cm}^{2}$ (current protocol II) whereas (the solid residue of) all other investigated samples represent hematite used as an additive (4.6-7 $\mathrm{g}$ in $125 \mathrm{~mL}$ of $0.05 \mathrm{M}$ $\mathrm{H}_{2} \mathrm{SO}_{4}$ ) to the electrolyte (exploited for carrying out long term electrolysis according to current protocol II at $10 \mathrm{~mA} / \mathrm{cm}^{2}$ (Table S1). The EPR spectra for both temperatures reveal clear differences between samples $26,29,30,33$ and 36 , and samples $37-39$. The first set of samples is characterized by EPR spectra exhibiting single, slightly asymmetric broad lines with almost Lorentzian shape that largely resemble that of pure hematite (Reference 1) with a reduced linewidth observed for samples 29-36. Nevertheless, additional features appear in the spectra recorded at $15 \mathrm{~K}$ with $\mathrm{g}$ values of $\sim 2.0$ and $\sim 4.5$, indicative for the presence of $\mathrm{Fe}^{3+}$ in a low symmetry environment ${ }^{51,52}$. Strikingly, for samples 37-39 the broad hematite EPR line has a significantly reduced amplitude and the additional features become prominent with an additional small signal appearing at $g=9.3$. These spectral features suggest that upon hydrolysis of a hematite suspension $\mathrm{Fe}^{3+}$ ions intercalate into $\mathrm{Fe}_{2} \mathrm{O}_{3}$, ending up in predominantly axially coordinated sites ${ }^{53,54}$. Notably, the intensity of these spectral features is comparable between the two sets of samples, indicating that about the same amount of $\mathrm{Fe}^{3+}$ ions incorporates into the $\mathrm{Fe}_{2} \mathrm{O}_{3}$ lattice, which on the other hand appears to be significantly influenced in samples 37-39. The spectra recorded for these samples at $296 \mathrm{~K}$ shows the presence of at least two spectral components with different resonance position and linewidth. One of these components (being strongest in sample 37) resembles that of pure hematite, whereas the other component(s) is strongly shifted towards higher g values, indicating an altered iron coordination in the hematite lattice. Nevertheless, the presence of the $\mathrm{g} \sim 4.5$ and $\mathrm{g} \sim 2$ signals in samples 26-36 with similar intensity largely rules out that the intercalated $\mathrm{Fe}^{3+}$ is solely responsible for rearrangement of 
the hematite lattice. Comparison with a reference sample containing $5 \%$ crystalline magnetite (Reference 2), that shows remarkably different EPR line shapes, indicates that no crystalline $\mathrm{Fe}_{3} \mathrm{O}_{4}$ is formed.

These results may therefore serve to underpin the proposed reaction of iron ions with hematite finally end up in the formation of amorphous iron oxide species.

To get more insight into the proposed $\mathrm{Fe}_{3} \mathrm{O}_{4}$ participation in the electrolysis of a hematite/ $\mathrm{Fe}_{2} \mathrm{O}_{3}$ mixture, we carried out an electrolysis of a sulfuric acid/ $/ \mathrm{Fe}_{2} \mathrm{O}_{3} / \mathrm{Fe}_{3} \mathrm{O}_{4}(125 \mathrm{~mL} 0.5 \mathrm{M} / 32 \mathrm{~g} / 1.1 \mathrm{~g}$; sample 45) mixture at constant current density of $30 \mathrm{~mA} / \mathrm{cm}^{2}$ upon usage of two Ni42 electrodes. The potential required to ensure a constant current density of $30 \mathrm{~mA} / \mathrm{cm}^{2}$ was found to be from the very start of the measurement very close to the constant value (Figure 12) to which it (after some hours) dropped down when solely hematite was used as an additive to the clear electrolyte (Figure 1a, black curve). This finding supports our assumption that electrocatalysis of a hematite $/ \mathrm{H}_{2} \mathrm{SO}_{4}$ suspension might occur through a temporary formation of $\mathrm{Fe}_{3} \mathrm{O}_{4}$ species.

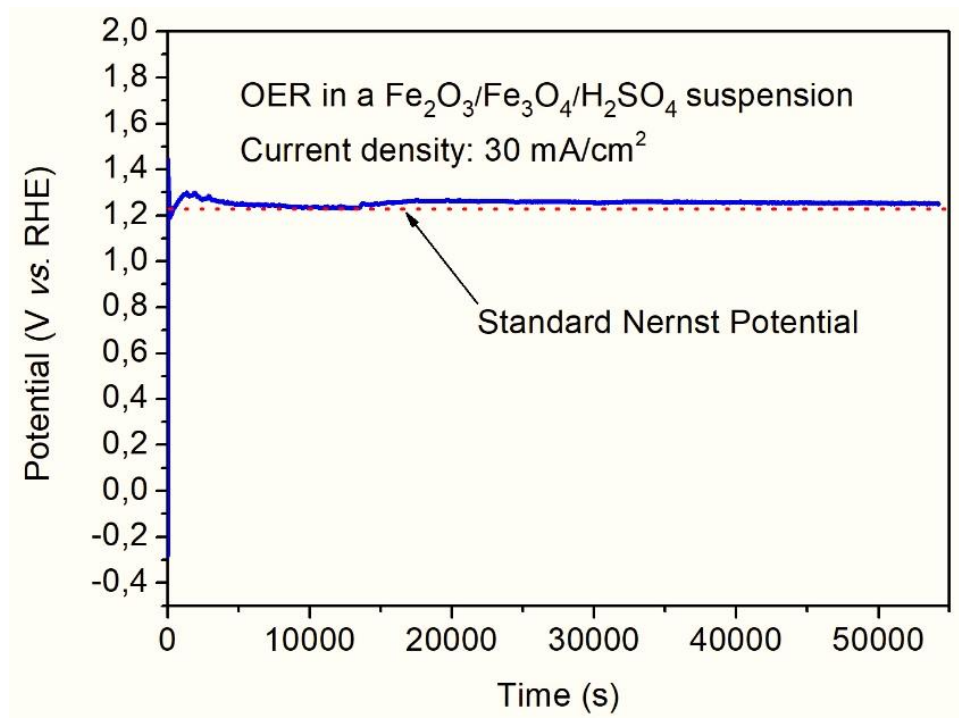

Figure 12. Chronopotentiometry measurement carried out with a $\mathrm{H}_{2} \mathrm{SO}_{4} / \mathrm{Fe}_{2} \mathrm{O}_{3} / \mathrm{Fe}_{3} \mathrm{O}_{4}$ suspension (125 mL $0.5 \mathrm{M} \mathrm{H}_{2} \mathrm{SO}_{4} ; 32 \mathrm{~g} \mathrm{Fe}_{2} \mathrm{O}_{3} ; 1.1 \mathrm{~g} \mathrm{Fe}_{3} \mathrm{O}_{4}$ ) upon usage of a platinum $\mathrm{CE}$ and a graphite WE. Current protocol I (See Table S1). Details see experimental part. 
In a final experiment we wanted to shed light on a potential depleting path for $\mathrm{Fe}_{3} \mathrm{O}_{4}$ which could also be useful to clarify its role whilst electrolysis of iron-oxide-sulfuric acid suspensions. Electrolysis of a $\mathrm{H}_{2} \mathrm{SO}_{4} / \mathrm{Fe}_{3} \mathrm{O}_{4}$ suspension ( $125 \mathrm{~mL} / 10 \mathrm{~g}$; sample 46 ) according to the standard current protocol I (Table S1) with a total duration of $60600 \mathrm{~s}$ resulted in a mass loss of $3 \mathrm{~g}$, i.e. $30 \%$ of the magnetite was spent. This is significantly more than the amount that is simply dissolved in sulfuric acid $(0.16 \mathrm{~g}$ in $125 \mathrm{~mL} 0.5 \mathrm{M} \mathrm{H}_{2} \mathrm{SO}_{4}$ ) thus under current-less condition. This cannot be regarded as hard proof for the correctness of reaction (4) as neither crystalline $\mathrm{Fe}_{3} \mathrm{O}_{4}$ was detected in the originally performed electrolysis of hematite/ $\mathrm{H}_{2} \mathrm{SO}_{4}$ suspensions, nor was crystalline $\mathrm{Fe}_{2} \mathrm{O}_{3}$ proven to exist in the solid residue after completion of this electrolysis of Magnetite $/ \mathrm{H}_{2} \mathrm{SO}_{4}$ suspension. Nevertheless, it can be considered as a proof of concept and as such it suggests the correctness of an electrocatalysis-based depletion route for magnetite (that is temporarily/in situ formed), as a depletion of magnetite solely based on a simple dissolution procedure would not lead to such a substantial loss of $\mathrm{Fe}_{3} \mathrm{O}_{4}$.

\section{Conclusions}

The efficient, economic, durable and environmentally friendly storage of electricity remains one of the big challenges modern society has to cope with. The battery solution can only be considered as an interim solution due to serious constrains like self- discharge, a decrease in storage capacity as the number of charge-discharge cycles increases, and an environmental impact in the production of lithium, just to name a few. For good reason, water-electrolysis is the most pathbreaking energy storage technique and if sourced by green energy allows a $\mathrm{CO}_{2}$ footprint free access to super clean hydrogen, the energy carrier of the future. So far, two serious problems related to electrocatalytically triggered water splitting have remained unsolved. 1. A substantial overpotential on the anode which keeps the cell voltage, the potential difference between cathode and anode high and-, as a direct consequence, the overall efficiency low. 2. Current energy conversion units must be resistant to frequent changes in the electricity load. Among the various techniques currently available (with respect to water-splitting based ones), only those of proton exchange membrane type can meet 
these requirements. PEM electrolyzers however require acidic electrolytes and all known electrode materials (even the noble ones!) are unstable in acids when positive potentials are applied. We have suggested an alternative electrolysis setup that takes advantage of simple steel as anode material and an electrolyte that solely consists of a hematite $/ \mathrm{H}_{2} \mathrm{SO}_{4}$ suspension. To ensure a semi-cellseparation both electrodes are inserted into plastic cartridges which still allows particles to flow from anode room to the cathode room and vice versa (Figure 6). The potential at which powerful oxygen evolution takes place is fascinatingly low (1.26 V vs. RHE at $30 \mathrm{~mA} / \mathrm{cm}^{2}$ current density, pH0). Moreover, the overall cell voltage is fascinatingly low $\left(1.6 \mathrm{~V}\right.$ at $30 \mathrm{~mA} / \mathrm{cm}^{2}$ current density, $\left.\mathrm{pH} 0\right)$. The weight-loss, determined for $\mathrm{Ni} 42$ after $50000 \mathrm{~s}$ of $\mathrm{CP}$ at $30 \mathrm{~mA} / \mathrm{cm}^{2}$ current density is unparalleled low $\left(22 \mu \mathrm{g} / \mathrm{mm}^{2}\right)$. Experiments suggest that $\mathrm{Fe}_{2} \mathrm{O}_{3}$ is converted to a $\mathrm{Fe}(\mathrm{II}) / \mathrm{Fe}(\mathrm{III})$ oxide species on the cathode which is then reconverted to (likely amorphous) $\mathrm{Fe}_{2} \mathrm{O}_{3}$ upon release of molecular oxygen on the anode. Thus, an electrocatalytically driven cyclic process involving molecular oxygen, water, and two different iron oxide species makes possible the splitting of water molecules in the gross reaction with almost incredible efficiency.

\section{Experimental section}

\section{Preparation of samples 1-23}

Electrolysis was performed in a $150 \mathrm{~mL}$ glass beaker upon usage of a WE prepared from Ni 42 steel (Schmiedetechnik Faulenbach, Wiehl, Germany) with a total geometry of 100x 10x $1.5 \mathrm{~mm}$ steel on which an apparent surface area of $2 \mathrm{~cm}^{2}$ was defined by an insulating tape (Kapton tape). Figure $\mathrm{S} 41$ shows the analysis certificate of Ni42 steel. Pre-treatment: prior to electrolysis the surface of the metal was cleaned intensively with ethanol and polished with grit $600 \mathrm{SiC}$ sanding paper. Afterwards the surface was rinsed intensively with deionised water and dried under air for $5 \mathrm{~h}$. The weight was determined using a precise balance (Sartorius 1712, $0.01 \mathrm{mg}$ accuracy) prior to polarization. A platinum wire electrode $\left(4.5 \mathrm{~cm}^{2}\right.$ geometric area) was employed as the $\mathrm{CE}$, a reversible hydrogen reference electrode (RHE, HydroFlex, Gaskatel Gesellschaft für Gassysteme durch Katalyse und 
Elektrochemie mbH. D-34127 Kassel, Germany) was utilized as the reference standard, therefore all voltages are quoted against this reference electrode (RE). The RHE was placed in between the WE and the CE. The distance between WE and RHE was $2 \mathrm{~mm}$. Sulfuric acid (Carl Roth, Karlsruhe, Germany; $\mathrm{C}=0.5 \mathrm{Mol} / \mathrm{L} ; 125 \mathrm{~mL}$ ) was filled in the glass beaker and in case of samples $1-5,9-23$ the corresponding amount of hematite (325 mesh, Alfa Aesar, Kandel, Germany, See Table S1) was (additionally) added under strong stirring. Figure $\$ 42$ shows the analysis certificate of hematite. Immediately, the three electrodes were immersed into the electrolyte in a way that complete coverage of the platinum electrode and the defined area of the WE were ensured. Stirring was applied to the electrolyte via a stirring bar $(40 \times 8 \mathrm{~mm})$. The stirring rate was adjusted according to Table S1. A stirring rate of 1.0 corresponds to $100 / \mathrm{min}$. For preparation of the samples electrolysis was realized upon applying a chronopotentiometry protocol (current protocol I, Table S1). After completion of the CP the anode was taken out of the electrolyte, washed with deionised water and dried in an oven at $42{ }^{\circ} \mathrm{C}$. Again, the weight was determined using a precise balance (Sartorius 1712 , $0.01 \mathrm{mg}$ accuracy). The electrolyte was centrifuged and the clear acid analysed via ICP-OES. The solid residue was dried in an over under air at $45^{\circ} \mathrm{C}$ for 24 hours. FTIR spectroscopic, photon electronspectroscopic and electron pair resonance spectroscopic investigations have been carried out with the powder.

\section{Preparation of samples 24-31 and 33-39}

In a modification of the previous description, the platinum electrode was replaced by a $\mathrm{Ni} 42$ electrode, which was created just like the first Ni42 electrode.

\section{Preparation of sample 32}

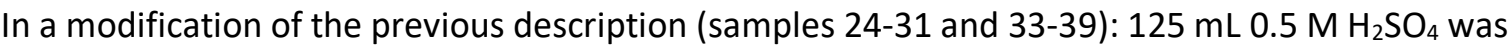
stirred with $35 \mathrm{~g} \mathrm{Fe}_{2} \mathrm{O}_{3}$ for $50000 \mathrm{~s}$. The suspension was filtered and the filtrate used as electrolyte for carrying out the CP-based preparation method (current protocol I see Table S1) described before. 


\section{Preparation of sample 40}

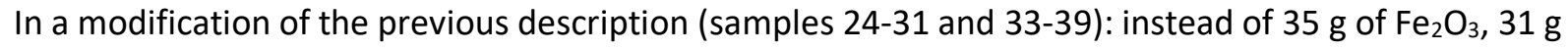
$\mathrm{Fe}_{2} \mathrm{O}_{3}+4 \mathrm{~g} \mathrm{Fe}(\mathrm{III})_{2}\left(\mathrm{SO}_{4}\right)_{3}$ were added.

\section{Preparation of sample 41}

In a modification of the previous description (samples $24-31$ and 33-39): instead of $35 \mathrm{~g}$ of $\mathrm{Fe}_{2} \mathrm{O}_{3}, 8 \mathrm{~g}$ $\mathrm{Fe}(\mathrm{III})_{2}\left(\mathrm{SO}_{4}\right)_{3}$ were added.

\section{Preparation of sample 43}

In a modification of the previous description (samples 1-23): The Ni42 WE has been replaced by a graphite electrode (Hangzhou Guhongni Electronic Co Ltd, Hangzhou, China; rod, 10 mm in diameter, $100 \mathrm{~mm}$ in length).

\section{Preparation of sample 44}

In a modification of the previous description (samples $24-31$ and 33-39): instead of $35 \mathrm{~g}$ of $\mathrm{Fe}_{2} \mathrm{O}_{3}, 30$ $\mathrm{g} \mathrm{Fe}_{2} \mathrm{O}_{3}+1.5 \mathrm{~g} \mathrm{Fe}(\mathrm{III})_{2}\left(\mathrm{SO}_{4}\right)_{3}+0.5 \mathrm{~g} \mathrm{Fe}(\mathrm{II})\left(\mathrm{SO}_{4}\right)$ were added.

\section{Preparation of sample 45}

In a modification of the previous description (samples 24-31 and 33-39): instead of $35 \mathrm{~g}^{\circ} \mathrm{Fe}_{2} \mathrm{O}_{3}, 32 \mathrm{~g}$ $\mathrm{Fe}_{2} \mathrm{O}_{3}+1.1 \mathrm{~g} \mathrm{Fe}_{3} \mathrm{O}_{4}$ were added.

\section{Preparation of sample 46}

In a modification of the previous description (samples $24-31$ and $33-39$ ): instead of $35 \mathrm{~g}$ of $\mathrm{Fe}_{2} \mathrm{O}_{3}, 10 \mathrm{~g}$ of $\mathrm{Fe}_{3} \mathrm{O}_{4}$ were added.

\section{Acknowledgements}

The authors thank Prof. Steinhoff (Physics department) for fruitful discussions and Prof. Wollschläger (Physics department), Prof. Steinhart, Prof. Reuter, Prof. Beginn, Prof. Walder and Prof. Haase (Chemistry department) for technical support. 
${ }^{1}$ P. Poizot, F. Dolhelm, Energy Environ. Sci., 2011, 4, 2003.

2 P. V. Kamat, J. Phys. Chem. C 2007, 111, 2834.

${ }^{3}$ R. J. Deetz, J. N. H. Reek and B. C. C. van der Zwaan, Energy Environ. Sci., 2018, 11, 1653.

${ }^{4}$ S. Baranton and C. Coutanceau, Appl. Catal. B, 2013, 136-137, 1.

${ }^{5}$ F. Le Formal, W. S. Bouree, M. S. Prevot and K. Sivula, Chimia, 2015, 69, 12, 789.

${ }^{6}$ M. G. Walter, E. L. Warren, J. R. McKone, S. W. Boettcher, Q. Mi, E. A. Santori and N. S. Lewis, Chem. Rev., 2010, 110, 6446.

${ }^{7}$ A. Kudo and Y. Miseki, Chem. Soc. Rev., 2009, 38, 253.

${ }^{8}$ H. Dau, C. Limberg, T. Reier, M. Risch, S. Roggan and P. Strasser, ChemCatChem, 2010, 2, 724.

${ }^{9}$ J. Suntivich, K. J. May, H. A. Gasteiger, J. B. Goodenough and Y. S. Horn, Science, 2011, 334, 1383.

${ }^{10}$ H. Schäfer and M. Chatenet, ACS Energy Lett., 2018, 3, 574.

${ }^{11}$ M. Wang, Z. Wang, X. Gong and Z. Guo, Renew. Sust. Energ. Rev., 2014, 29, 573.

12 B. S. Yeo and A. T. Bell, J. Am. Chem. Soc., 2011, 133, 5587.

${ }^{13}$ Y. Lee, J. Suntivich, K. J. May, E. E. Perry and Y. Shao-Horn, J. Phys. Chem. Lett., 2012, 3, 399.

${ }^{14}$ E. Detsi, J. B. Cook, B. K. Lesel, C. L. Turner, Y.-L. Liang, S. Robbennolt and S. H. Tolbert, Energy Environ. Sci., 2016, 9, 540.

${ }^{15}$ H. Schäfer, S. Sadaf, L. Walder, K. Kuepper, S. Dinklage, J. Wollschlaeger, L. Schneider, M. Steinhart, J. Hardege and D. Daum, Energy Environ. Sci., 2015, 8, 2685.

${ }^{16}$ H. Schäfer, D. M. Chevrier, K. Kuepper, P. Zhang, J. Wollschläger, D. Daum, M. Steinhart, C. Hess, U. Krupp and K. Müller-Buschbaum, Energy Environ. Sci., 2016, 9, 2609.

${ }^{17}$ H. Schäfer, K. Kuepper, M. Schmidt, K. Müller-Buschbaum, D. Daum, M. Steinhart, W. Han, J. Wollschläger, U. Krupp, P. Hou, J. Stangel and X. Liu, Catal. Sci. Technol., 2018, 8, 2104.

${ }^{18}$ H. Schäfer, K. Kuepper, K. Muller-Buschbaum, D. Daum, M. Steinhart, J. Wollschlaeger, U. Krupp, M. Schmidt, W. Han and J. Stangl, Nanoscale, 2017, 9, 17829.

${ }^{19}$ M. Bernt, A. Hartig-Weiß, M. F. Tovini, H. A. El-Sayed, C. Schramm, J. Schröter, C. Gebauer and H. A. Gasteiger, Chem. Ing. Tech., 2020, 92, 1-2, 1-10, DOI:10.1002/cite.201900101.

${ }^{20}$ C. C. L. McCrory, S. Jung, J. C. Peters and T. F. Jaramillo, J. Am. Chem. Soc., 2013, 135, 45, 16977.

${ }^{21}$ C. C. L. McCrory, S. Jung, I. M. Ferrer, S. M. Chatman and I. C. Peters, J. Am. Chem. Soc., 2015, 137, 4347.

${ }^{22}$ N. Danilovicet, R. Subbaraman, K.-C. Chang, S. H. Chang, Y. I. Kang, J. Snyder, A. P. Paulikas, D. Strmcnik, Y.-T. Kim, D. Myers, V. R. Stamenkovic and N. M. Markovic, J. Phys. Chem. Lett., 2014, 5, 2474.

${ }^{23}$ T. Reier, M. Oezaslan and P. Strasser, ACS Catal., 2012, 2, 8, 1765.

${ }^{24}$ K. Sardar, E. Petrucco, C. I. Hiley, J. D. B. Sharman, P. P. Wells, A. E. Russell, R. J. Kashtiban, J. Sloan and R. I. Walton, Angew. Chem.Int. Ed., 2014, 53, 10960.

${ }^{25}$ T. Audichon, S. Morisset, T. W. Napporn, K. B. Kokoh, C. Comminges and C. Morais, ChemElectroChem, 2015, 2, 1128.

${ }^{26}$ L. C. Seitz, C. F. Dickens, K. Nishio, Y. Hikita, J. Montoya, A. Doyle, C. Kirk, A. Vojvodic, H. Y. Hwang, J. K. Norskov and T. F. Jaramillo, Science, 2016, 353, 6303, 1011.

${ }^{27}$ P. A. DeSario, C. N. Chervin, E. S. Nelson, M. B. Sassin and D. R. Rolison, ACS Appl. Mater. Interfaces, 2017, 9, 2387.

${ }^{28}$ A. L. Strickler, D. Higgins and T. F. Jaramillo, ACS Appl. Energy Mater., 2019, 2, 5490.

${ }^{29}$ J. Zhang, S. Eslava, Sustainable Energy Fuels, 2019, 3, 1351.

${ }^{30}$ D. A. Wheeler, G. Wang, Y. Ling, Y. Li, J. Z. Zhang, Energy Environ. Sci., 2012,5, 6682

${ }^{31}$ J. Yang , G. Zhu, Y. Liu , J. Xia , Z. Ji , X. Shen, S. Wu, Adv. Funct.Mater., 2016, 26, 4712.

${ }^{32}$ S. Shen, S. A. Lindley, X. Chen and J. Z. Zhang, Energy Environ. Sci., 2016, 9, 2744.

33 D. K. Bora, A. Braun and E. C. Constable, Energy Environ. Sci., 2013, 6, 407.

${ }^{34}$ H. Schäfer, K. Kuepper, J. Koppe, P. Selter, M. Steinhart, M. R. Hansen and D. Daum, ACS Catal., 2018, 8, 11, 10914.

${ }^{35}$ L. Yang, G. Yu, X. Ai, W. Yan, H. Duan, W. Chen, X. Li, T. Wang, C. Zhang, X. Huang, J.-S. Chen and X. Zou, Nat. Commun., 2018, 9, 5236.

${ }^{36}$ W. Zhou, X.-J. Wu, X. Cao, X. Huang, C. Tan, J. Tian, H. Liu, J. Wang and H. Zhang, Energy Environ. Sci., 2013, 6, 2921.

${ }^{37}$ L. Zhou, A. Shinde, J. H. Montoya, A. Singh, S. Gul, J. Yano, Y. Ye, E. J. Crumlin, M. H. Richter, J. K. Cooper, H. S. Stein, J. A. Haber, K. A. Persson and J. M. Gregoire, ACS Catal., 2018, 8, 10938.

${ }^{38}$ Y. Qiu, L. Xin and W. Li, Langmuir, 2014, 30, 7893. 


\footnotetext{
${ }^{39}$ U. Schwertmann, Plant and Soil, 1991, 130, 1.

${ }^{40}$ A. M. Odnovolova, D. S. Sofronov, A. N. Puzan, V. N. Baumer, P. V. Mateychenko, S. M. Desenko, O. M. Vovk, K. A. Mozul and E. Yu. Bryleva, Funct. Mater., 2015, 22, 4, 475.

${ }^{41}$ L. Hu, A. Khaniya, J. Wang, G. Chen, W. E Kaden and X. Feng, ACS Catal., 2018, 8, 9312.

${ }^{42}$ S. C. Pang, S. F. Chin and M. A. Anderson, J. Colloids. Interf. Sci., 2007, 311, 94.

${ }^{43}$ Handbook of Chemistry and Physics, 79 th Edition (Ed. D. R Lide), CRC Press, New York, 1998, pp 5-16, 5-85

${ }^{44}$ S. I. Srikrishna Ramya and C. K. Mahadevan, Mater. Lett., 2012, 89, 111.

${ }^{45}$ X. Cao and R. Prozorov, J. Mater. Res., 1997, 12, 2, 402.

${ }^{46}$ J. Wang, N. Zhang, J. Su and L. Guo, RSC Adv., 2016, 6, 41060.

${ }^{47}$ H. Schäfer, D. M. Chevrier, P. Zhang, K. Kuepper, J. Stangl,K. M. Müller-Buschbaum, J. D. Hardege, K. Kuepper, J. Wollschlaeger, U. Krupp, S. Duehnen, M. Steinhart, L. Walder, S. Sadaf and M. Schmidt, Adv. Funct. Mater., 2016, 20, 35, 6402.

${ }^{48}$ J. P. Hoare in Advances in Electrochemistry and Electrochemical Engineering, Vol. 6 (Eds.: P. Delahay, C. W. Tobias), Interscience, New York, 1966, pp. $201-288$.

${ }^{49}$ C. C. Tseung and S. Jasem, Electrochim. Acta, 1977, $22,31$.

${ }^{50}$ M. Pourbaix in Atlas d_Equilibres Electrochemiques a 25 8C, Gauthiers-Villars, Paris, 1963.

${ }^{51}$ B. R. Angel and W. E. J. Vincent, Clays and Clay Minerals, 1978, 26, 4, 263.

${ }^{52}$ A. M. Hofmeister and G. R. Rossman, Phys. Chem. Minerals, 1984, 11, 213.

${ }^{53}$ R. M. Golding, M. Kestigian and C. W. Tennant, J. Phys. C: Solid State Phys., 1978, 11, 5041.

${ }^{54}$ J. K. Grady, A. B. Mason, R. C. Woodworth and N. D. Chasteen, Biochem. J., 1995, 309, 2, 403.
} 